\title{
LA REDUCCIÓN AL ABSURDO COMO ARGUMENTO JURÍDICO*
}

\author{
Joaquín Rodríguez-Toubes Muñiz \\ Universidad de Santiago de Compostela
}

RESUMEN. Mediante la reducción al absurdo, reductio ad absurdum o argumento apagógico se defiende una tesis mostrando que rechazarla tiene implicaciones absurdas porque lleva a una contradicción. El argumento tiene distintas variantes, y es más o menos concluyente, dependiendo de su lógica interna y de la justificación de la premisa que se considera absurdo negar. Este trabajo discute la tipología y algunos problemas específicos que presenta este argumento en el razonamiento jurídico, en particular su naturaleza lógica, su relación con el ideal de coherencia del ordenamiento jurídico, su proximidad con los argumentos consecuencialistas y su carácter emotivo y potencialmente falaz. Además se muestran y clasifican varios ejemplos de uso del argumento en la motivación de decisiones jurídicas.

Palabras clave: reductio ad absurdum, argumentación jurídica, motivación judicial.

ABSTRACT. By means of the reductio ad absurdum or apagogical argument a thesis is argued showing that its denial has absurd implications because it leads to a contradiction. The argument has different variations, and it is more or less conclusive, depending on its inner logic and on the justification of the premise whose denial is regarded as absurd. This paper discusses the typology and some of the specific problems shown by this argument in legal reasoning, particularly its logical nature, its relation with the ideal of coherence or the legal order, its vicinity with consequentialist arguments and its emotive and potentially fallacious character. Moreover, several examples of use of the argument in the motivation of legal decisions are offered and classified.

Keywords: reductio ad absurdum, legal argumentation, judicial justification.

* Fecha de recepción: 7 de junio de 2012. Fecha de aceptación: 3 de julio de 2012. 


\section{INTRODUCCIÓN ${ }^{1}$}

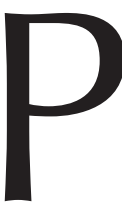

or reducción al absurdo, reductio ad absurdum o argumento apagógico ${ }^{2}$ se conoce un modo de argumentar, empleado con cierta frecuencia en el razonamiento jurídico, que consiste en defender una tesis mostrando que rechazarla tiene implicaciones absurdas porque lleva a una contradicción. Dicho de otro modo, el argumento consiste en refutar una hipótesis por sus implicaciones absurdas con el fin de fundamentar otra tesis alternativa. El argumento tiene distintas variantes, y es más o menos concluyente, dependiendo del rigor lógico de su planteamiento y de la justificación de la premisa que se considera absurdo negar. En este trabajo pretendo ampliar las escuetas presentaciones de esta técnica que recogen los textos sobre argumentación jurídica. Precisaré primero sus características y variantes, poniendo algunos ejemplos de uso en la motivación de decisiones de órganos judiciales y del Tribunal Constitucional ( $\$ 1$ ). A continuación, examinaré algunos de los

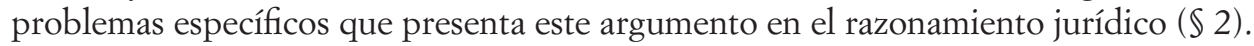

\section{EL USO JURÍDICO DE LA REDUCCIÓN AL ABSURDO}

\subsection{El argumento: descripción y tipología}

El argumento por reducción al absurdo, tal como se emplea en el razonamiento jurídico, fundamenta una tesis mostrando que su negación u otras alternativas conducen lógicamente a un resultado imposible o de otro modo inaceptable, y en último término a la contradicción de negar lo que a la vez se acepta explícita o implícitamente como premisa. Se trata de una aplicación peculiar de una conocida forma de demostración lógica y matemática, pues en el ámbito jurídico no sólo se emplea como prueba deductiva, sino también como instrumento retórico o dialéctico para defender la tesis considerada más idónea o razonable.

El argumento por reducción al absurdo puede entenderse de varias maneras:

a) En su sentido más estricto o fuerte, el lógico y matemático, el argumento demuestra una tesis probando que, dadas ciertas premisas, de la hipótesis que la niega se deduce una contradicción, con lo cual negar la tesis es una imposibilidad lógica. Por tanto es una prueba por contradicción e indirecta, y así se denomina también en ocasiones este argumento.

1 El presente trabajo se integra en el Proyecto de investigación DER2010-19897-C02-02. Una versión incipiente fue sometida como comunicación a un encuentro de investigadores organizado por el Proyecto. Agradezco a los compañeros del proyecto de investigación los comentarios realizados a borradores de este trabajo.

2 La denominación «argumento apagógico» proviene de la palabra griega ỏ $\pi \alpha \gamma \omega \gamma \eta \dot{~(a p a g o ̄ g e, ~ l l e v a r s e), ~}$

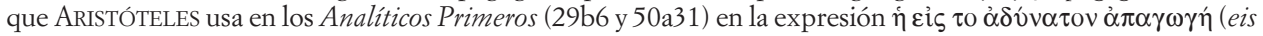
tò adýnaton apagōgè), traducible como «reducción a lo imposible» (ARISTÓTELES, ed. 1998: 125 y 214). Pero en la misma obra emplea otras expresiones para referirse a la reducción al absurdo, por ejemplo: eis tò adýnaton ágontas (op. cit., 27 a 15, p. 110). Además, $\alpha \pi \alpha \gamma \omega \gamma \eta ́$ o «reducción» es también el nombre que da ARISTÓTELES a un tipo de razonamiento distinto tanto de la deducción como de la inducción (op. cit., 69 a 20, p. 290), y al que PEIRCE dio el nombre de abducción (vid, por ejemplo, BEUCHOT, 1998). Sobre la confusión entre apagōgē (abducción) y reducción al absurdo, vid. también AGUIRRE, 2002. 
b) En un sentido algo menos estricto, el argumento consiste en rechazar una hipótesis (para defender otra alternativa) mostrando que tiene como consecuencia lógica una falsedad o imposibilidad fáctica; o algo que se tiene generalmente por falso. Aquí cabe una subdivisión, y así RESCHER (2005) distingue entre consecuencia falsa (argumentos ad falsum o ad impossibile) e implausible o anómala (argumentos ad ridiculum $\mathrm{o}$ ad incommodum).

c) En un sentido todavía más amplio, el argumento rechaza una hipótesis (para defender otra alternativa) mostrando que tiene una consecuencia lógica inadmisible o inaceptable por ser incoherente con el sistema de referencia. Con esto el argumento puede tomar un cariz axiológico o teleológico ${ }^{3}$. El nombre de argumento ab absurdo, usado a veces, se corresponde mejor con esta versión menos rigurosa, que puede degenerar fácilmente en falacia. Pero conviene distinguir entre la reducción al absurdo y otros argumentos diferentes basados en las consecuencias. La reducción al absurdo se fija en las implicaciones lógicas de una hipótesis, mientras que la argumentación consecuencialista atiende a los efectos que probablemente causará su puesta en práctica. Además, los argumentos consecuencialistas pueden orientarse a evitar resultados simplemente indeseables o inconvenientes; mientras que la reducción al absurdo más bien trata de denunciar la incongruencia. Sobre la diferencia entre argumentación ad absurdum y consecuencialista volveré más adelante (infra \$2.6).

La anterior clasificación describe las variedades de uso del argumento más que diferencias en su estructura lógica, y por esta razón es algo engañosa. En su estructura las tres variantes pueden reducirse a la primera, pues en todos los casos el argumento consiste en poner de manifiesto una contradicción lógica. La variedad estriba en el origen de la contradicción. En todos los casos el objetivo del argumento es hacer patente que afirmar una cierta hipótesis implica negar una tesis previamente asumida, a la que llamaré premisa de contraste, y que para evitar esa conclusión imposible lógicamente (a saber: que la premisa de contraste es a la vez verdadera y falsa) necesariamente hay que abandonar dicha hipótesis en favor de su alternativa. Las diferencias, por tanto, no están en el núcleo del argumento sino más bien en la naturaleza de la premisa de contraste. En la primera variante, esta premisa forma parte del propio argumento que contiene la hipótesis que se rechaza. La reducción al absurdo simplemente la reutiliza para refutar esa hipótesis mostrando que ésta conduce a negar aquella premisa y, con ello, que el argumento es internamente inconsistente. En la segunda variante la premisa de contraste es un dato empírico que el argumento propuesto pasaba por alto. Aquí la reducción al absurdo muestra que la hipótesis rival conduce a negar ese hecho, y por tanto que es falsa. En la tercera variante la premisa de contraste es una tesis sobre lo que es congruente con el sistema de referencia; por ejemplo, con el derecho que interpretan de modo enfrentado la hipótesis que se rechaza y la alternativa que se defiende.

Las diferencias en la naturaleza de la premisa de contraste repercuten en la fuerza del argumento y justifican la clasificación propuesta. Para confiar en un argumento

3 Dice KLug [(1982) 1990: 196]: «Cuando se trata del argumento ad absurdum que aparece en la jurisprudencia [...], habrá que averiguar caso por caso si cuando se invoca dicho argumento lo que se quiere indicar es la estructura lógica de la respectiva inferencia, o si por el contrario lo que se quiere es más bien formular un juicio teleológico». En efecto, la reducción al absurdo tiene interés como argumento jurídico tanto en su forma lógica rigurosa como en usos no estrictamente deductivos (al respecto: ATIENZA, 2006: 155 y ss.). En todo caso, nada de esto desmiente el carácter sustancialmente lógico del argumento, como veremos. 
por reducción al absurdo, o en cualquier otro, se requiere que sea lógicamente válido (justificación interna) y además que sea sólido, en el sentido de que sus premisas sean verdaderas o suficientemente plausibles (justificación externa). En la reducción al absurdo del primer tipo a) las premisas son las del argumento rival y éste se rechaza por su inconsistencia, para cuya demostración basta la justificación interna. En cambio, en sus variantes de $b$ ) verdad empírica y de $c$ ) tesis sobre la coherencia, la premisa de contraste puede ser controvertida y demanda un fundamento independiente, que es más complicado de obtener en el último caso. Reducir al absurdo una hipótesis es hacer ver que conduce a negar una tesis que a la vez se afirma, y en esta contradicción consiste el absurdo; pero unas veces esa tesis afirmada (la premisa de contraste) acompaña originalmente a la hipótesis y otras veces es una tesis empírica o interpretativa presupuesta posteriormente por la reducción. Así pues, la reducción al absurdo pone de manifiesto que la hipótesis lleva (a) a contradecir sus propias premisas de partida, y por ello a una inconsistencia; o b) a contradecir un hecho conocido, y por ello a una falsedad; o $c$ ) a contradecir una interpretación pacífica sobre el contexto de la hipótesis, y por ello a una incoherencia. En todos los casos el absurdo es una contradicción, pero en los dos últimos la connotación es una falsedad o una incoherencia. Además, esta connotación ocupa el primer plano cuando la tesis empírica o interpretativa que se presupone (y cuya negación crea un absurdo) no es explicitada tampoco al efectuar la reducción al absurdo, como no suele serlo en el ámbito jurídico, de manera que el argumento viene a decir que la hipótesis es absurda porque implica una falsedad o una incoherencia, aunque formalmente dice que es absurda porque implica una contradicción con una premisa presupuesta.

Hasta aquí hemos visto distintas variantes del argumento por reducción al absurdo en función del tipo de implicación que se rechaza. Una segunda fuente de variaciones es qué se tome como hipótesis alternativa de la tesis que se pretende fundamentar. En la versión más genuina de la reducción al absurdo, la demostración deductiva lógica y matemática, se refuta la negación de la tesis que se pretende probar. Sin embargo, en el razonamiento jurídico la calificación de absurdo se dirige contra una hipótesis alternativa de la tesis que se defiende y no siempre contra su negación directa. Obviamente ambas versiones convergen cuando hay solamente dos alternativas, la tesis defendida y una hipótesis rival, de manera que refutar ésta equivale a afirmar aquélla, y viceversa ${ }^{4}$. En ocasiones, no obstante, la tesis que se quiere defender tiene más de una alternativa, de modo que refutar algunas de ellas no basta para probar dicha tesis, sino que habría que refutarlas todas.

En vista de lo expuesto, podemos reiterar que el argumento por reducción al absurdo, tal como se emplea en el razonamiento jurídico, fundamenta una tesis mostrando que su negación u otras alternativas conducen lógicamente a un resultado imposible o de otro modo inaceptable. Según esta caracterización amplia del argumento, cabe distinguir en él tres variantes, con sendas versiones excluyentes no excluyentes, las

\footnotetext{
${ }^{4}$ Según MarTínez ZorRilla (2010: 79), «el argumento apagógico resulta bastante débil si es el único que se utiliza en apoyo de la interpretación propuesta, ya que no ofrece argumento alguno a favor de ésta, sino tan sólo en contra de otra alternativa posible». Pero para demostrar $T$ es suficiente argumento que $\neg T$ es falso. Además la reducción al absurdo también tiene cabida para defender una tesis mediante la refutación no exhaustiva de sus alternativas, porque refuerza la tesis defendida como una solución que evita el absurdo y puede ser aceptada.
} 
cuales se representan en la siguiente tabla resumen y desarrollaré a continuación con algunos ejemplos ${ }^{5}$.

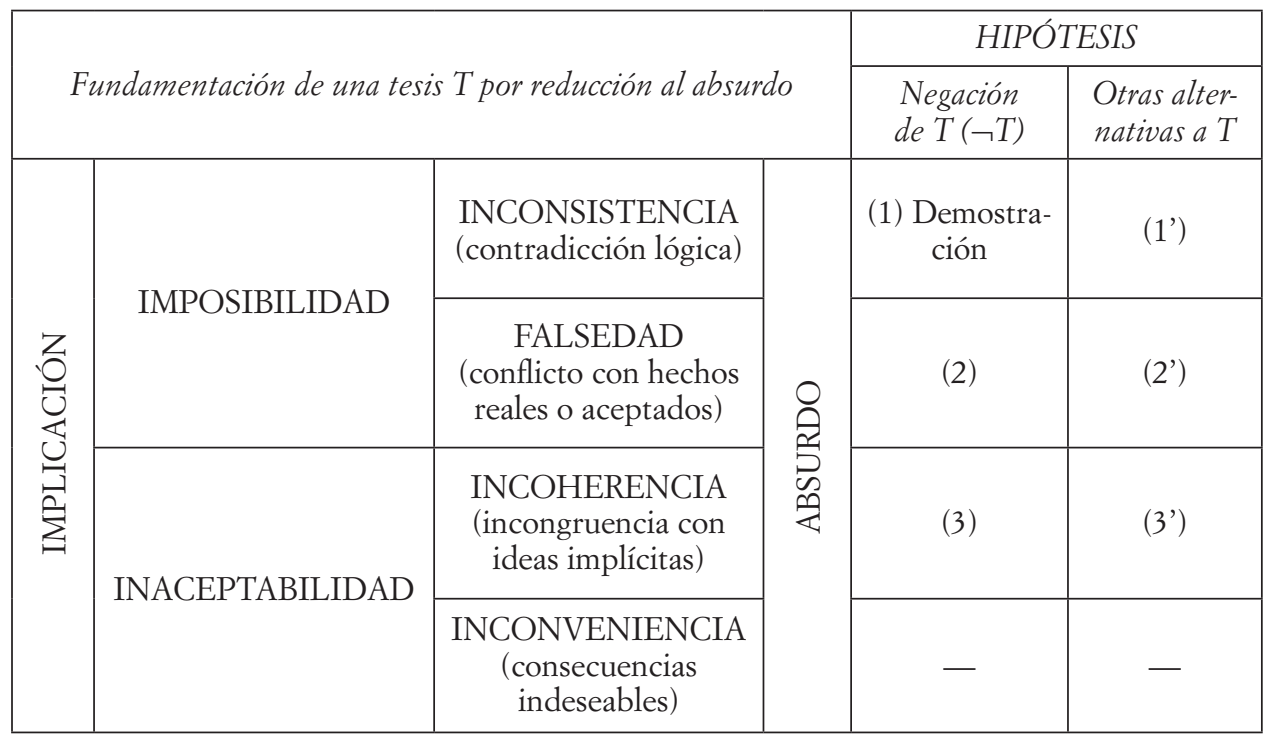

\subsection{Absurdo por inconsistencia}

El modo más ortodoxo y efectivo de emplear la reducción al absurdo es mostrar que la hipótesis rival conduce a un resultado incompatible con las premisas asumidas al formularla; esto es, que quien formula esa hipótesis se contradice y su razonamiento resulta insostenible y absurdo. Hay, entonces, una afinidad entre argumentar a favor de una tesis reduciendo al absurdo la hipótesis opuesta y rechazar la hipótesis opuesta porque su defensa es un razonamiento absurdo. El argumento que sostiene la hipótesis opuesta se rechaza en un caso porque hay en él una inconsistencia implícita; y en otro porque es inconsistente de modo evidente y explícito. Aunque el segundo modo de argumentar no es una reducción al absurdo, creo que merece la pena poner de relieve esta afinidad.

\subsubsection{Inconsistencia implícita}

La reducción al absurdo pone de manifiesto una contradicción implícita en un razonamiento. Refuta un razonamiento no por ser evidentemente ilógico o absurdo,

5 Otros estudios enumeran y clasifican modalidades de la reducción al absurdo en la motivación de decisiones del Tribunal Constitucional y de órganos jurisdiccionales; por ejemplo: EZQUIAGA, 1987; o FERNÁNDEZ AbAD y Estremera CEBrián, 1995. Aunque me guío también por esos estudios, la clasificación que sigue se basa en la tipología expuesta, según la cual el argumento en su uso jurídico muestra que una cierta hipótesis conduce a resultados: $a$ ) inconsistentes con sus premisas, $b$ ) falsos o $c$ ) incoherentes desde el punto de vista jurídico. 
sino por implicar una conclusión ilógica o absurda que parece pasar desapercibida. El argumento denuncia en el razonamiento rival una inconsistencia que no es inmediatamente visible, pero que una vez sacada a la luz invalida dicho razonamiento. Ahora bien, para lograr este efecto, el argumento ad absurdum debe contar con premisas sólidas y respetar la lógica. El siguiente ejemplo puede ilustrar la utilización correcta e incorrecta de la reducción al absurdo.

Sentencia del Tribunal Supremo (Civil), 464/2010, de 20 de julio de 2010

Se discutía la interpretación de un contrato de seguro. El descuido de un empleado del parque de atracciones de Madrid durante trabajos de mantenimiento provocó un accidente que causó daños en una máquina. La sociedad que explotaba el parque tenía una póliza llamada «Riesgo básico: todo riesgo daños materiales», que cubría los daños causados por un hecho «súbito, accidental e imprevisible». En cambio excluía el riesgo «avería de maquinaria», cubierto por una póliza opcional y definido como «los daños y/o pérdidas sufridos por las máquinas aseguradas, como consecuencia de una causa accidental, súbita e imprevisible de origen interno, no clasificada como riesgo excluido, ocasionados por: 1. Impericia, negligencia y actos malintencionados del personal del Asegurado o de extraños [...]». La compañía aseguradora entendió que los daños no estaban cubiertos por el seguro, y el conflicto llegó a juicio. La primera sentencia falló que el daño estaba cubierto, porque la causa del siniestro no tuvo un origen interno. La Audiencia Provincial de Madrid revocó esa decisión porque el riesgo cubierto eran los daños causados por un hecho «súbito, accidental e imprevisible» y sin embargo el accidente en este caso no era imprevisible sino que había sido causado por un error humano y podían haberse tomado medidas de precaución para evitarlo. Esta resolución fue a su vez casada por el Tribunal Supremo, que sostuvo lo siguiente (FJ 3. ${ }^{\circ}$ ):

[L]a interpretación del concepto «imprevisible» por el tribunal sentenciador conduce al absurdo de que una póliza «Todo Riesgo» no cubriera el debido al error humano y sí, solamente, los daños debidos a fuerza mayor.

Que tal interpretación no se ajusta a los arts. 1.284 y 1.286 CC $^{6}$ se advierte en seguida porque, de aceptarse, resulta que ni siquiera habiéndose contratado la garantía opcional de «Avería de Maquinaria» el seguro habría cubierto el siniestro, pues en tal caso también los daños tendrían que deberse a una causa «accidental, súbita e imprevisible», siendo así que la cobertura de esta garantía sí comprende muy expresamente los daños ocasionados por «impericia, negligencia y actos malintencionados del personal del asegurado o de extraños», demostración palpable de que en el contrato de seguro litigioso la imprevisibilidad es plenamente compatible con la negligencia de los empleados de la asegurada demandante.

En la motivación del Tribunal Supremo pueden reconocerse dos argumentos que se presentan como reducciones al absurdo, con desigual fuerza lógica. Un primer argumento parecería ser que es absurdo que una póliza «todo riesgo» excluya los daños causados por un error humano, porque (se sobreentiende) si es todo riesgo ha

6 Art. 1.284 CC: «Si alguna cláusula de los contratos admitiere diversos sentidos, deberá entenderse en el más adecuado para que produzca efecto». Art. 1.286 CC: «Las palabras que puedan tener distintas acepciones serán entendidas en aquella que sea más conforme a la naturaleza y objeto del contrato». 
de cubrir también ese riesgo. Este argumento podría tener atractivo retórico, pero es muy débil. La denominación «todo riesgo» de una póliza de seguros no significa que incluya todos los riesgos, ni tampoco el debido a error humano. En el presente caso, por ejemplo, no se discute que la póliza «todo riesgo» excluye los daños previsibles; y está claro que excluye las averías de maquinaria causadas por negligencia, las cuales están cubiertas por un seguro opcional. Además, aquí la premisa de contraste sería la misma conclusión que se quiere demostrar, por lo que el razonamiento sería circular, una petición de principio (vid. infra $\$ 2.9$ ). Vendría a decirse que en el caso presente el daño debido a error humano no queda excluido del seguro «todo riesgo» porque es absurdo que un seguro «todo riesgo» excluya el daño debido a error humano.

Según el segundo argumento, es absurdo que todo daño causado por negligencia se considere previsible, porque en otro caso carecería de sentido la póliza opcional de avería de maquinaria, la cual cubre daños causados por negligencia siempre que sean imprevisibles. Este argumento sí tiene consistencia lógica y es una eficaz reducción al absurdo. La posibilidad de que haya daños negligentes e imprevisibles cubiertos por un seguro hace efectivamente absurdo afirmar que los daños negligentes son siempre previsibles y prueba la tesis contraria, según la cual no todos los daños negligentes son previsibles ${ }^{7}$.

\subsubsection{Inconsistencia explícita}

Distinto de la reducción al absurdo, aunque afín a ella, es el argumento que desacredita una tesis al mostrar que se fundamenta en un razonamiento que es ilógico o absurdo de modo patente o explícito. En el terreno jurídico, este último argumento tiene un reflejo visible en el criterio jurisprudencial que hace anulables las decisiones judiciales que carecen de una motivación mínimamente racional, porque son arbitrarias y vulneran el derecho a la tutela judicial efectiva. Se reprocha el error judicial que consiste en violentar la lógica, no el error en la decisión que violenta los hechos o el derecho. El absurdo y la arbitrariedad pueden darse tanto en la apreciación de la prueba y la fijación de los hechos, como en la interpretación y aplicación del derecho ${ }^{8}$. El criterio del Tribunal Constitucional para apreciar que una argumentación es absurda se recoge en su Sentencia 164/2002, de 17 de septiembre (FJ 4. ${ }^{\circ}$ ):

$[\mathrm{L}] \mathrm{a}$ validez de un razonamiento desde el plano puramente lógico es independiente de la verdad o falsedad de sus premisas y de su conclusión pues, en lógica, la noción fundamental es la coherencia y no la verdad de hecho, al no ocuparse esta rama del pensamiento de verdades materiales, sino de las relaciones formales existentes entre ellas. Ahora bien, dado que es imposible construir el Derecho como un sistema lógico puro este Tribunal ha

7 Cuestión distinta es si era eso lo discutido. Si lo que sostuvo la Audiencia Provincial de Madrid no fue que toda negligencia implica previsibilidad, sino que en el caso juzgado hubo negligencia y previsibilidad (es decir, que la coincidencia de negligencia y previsibilidad fue contingente pero no era necesaria), entonces tampoco el segundo argumento del Tribunal Supremo es efectivo, y el supuesto absurdo que denuncia se desvanece.

${ }^{8}$ Un resumen de criterios para considerar que la apreciación judicial de la prueba es absurda y arbitraria puede verse en la Sentencia del Tribunal Supremo (Civil, Sección 1. ${ }^{a}$ ) de 1 de junio de 2011 (FD 4. ${ }^{\circ}$ ). En cuanto a la interpretación o la aplicación del derecho hay un resumen en la Sentencia del Tribunal Supremo (Contencioso-Administrativo, Sección 2.a) de 3 de octubre de 2008 (FD 3..$^{\circ}$. 
unido a la exigencia de coherencia formal del razonamiento la exigencia de que el mismo, desde la perspectiva jurídica, no pueda ser tachado de irrazonable. A tal efecto, es preciso señalar, como lo ha hecho este Tribunal, que no pueden considerarse razonadas ni motivadas aquellas resoluciones judiciales que, a primera vista y sin necesidad de mayor esfuerzo intelectual y argumental, se comprueba que parten de premisas inexistentes o patentemente erróneas o siguen un desarrollo argumental que incurre en quiebras lógicas de tal magnitud que las conclusiones alcanzadas no pueden considerarse basadas en ninguna de las razones aducidas.

Como ejemplo de argumentación manifiestamente absurda podría citarse la que censura el Tribunal Constitucional en su Sentencia 151/2001, de 2 de julio. En ella estima un recurso de amparo contra la inadmisión por el Tribunal Supremo de un recurso para unificación de doctrina interpuesto porque el Tribunal Superior de Justicia de Asturias había resuelto en una sentencia que en cierta fecha el contrato de trabajo del recurrente estaba en vigor y en otra sentencia que estaba extinguido. El TC razona así (FJ 4. $\left.{ }^{\circ}\right)$ :

$\mathrm{Y}$ aunque es verdad que unas mismas pruebas pueden conducir a considerar como probados o no probados los mismos hechos por los Tribunales de Justicia, también lo es que, afirmada la existencia de los hechos por los propios Tribunales de Justicia no es posible separarse luego de ellos sin acreditar razones ni fundamentos que justifiquen tal apartamiento. Y ello porque, en la realidad jurídica, esto es, en la realidad histórica relevante para el derecho, no puede admitirse que algo es y no es, que unos mismos hechos ocurrieron y no ocurrieron [...], cuando la contradicción no deriva de haberse abordado unos mismos hechos desde perspectivas jurídicas diversas [...], y es claro que unos hechos idénticos no pueden existir y dejar de existir para los órganos del Estado, pues a ello se oponen principios elementales de lógica jurídica y extrajurídica [...].

\subsection{Absurdo por falsedad}

Una segunda modalidad de reducción al absurdo toma como premisa de contraste una proposición que se supone verdadera, y el argumento consiste en refutar una hipótesis (para fundamentar una tesis alternativa) mostrando que implica el absurdo de negar esa proposición verdadera. En el uso jurídico de la reducción al absurdo cabe distinguir si la falsedad es por contraste con hechos del mundo (falsedad fáctica) o con datos jurídicos (falsedad jurídica).

\subsubsection{Falsedad fáctica}

A menudo los órganos judiciales rechazan un argumento o una tesis por considerar que lo que sostiene o implica no se corresponde con la realidad; y en ocasiones recurren para ello a la reducción al absurdo. Cuando así lo hacen dan por supuesto que el contraste con la realidad al que conduce esa posición es tan palmario que sería absurdo mantener la hipótesis una vez notada su implicación. El argumento se basa en mostrar la implicación, pero el rechazo se basa en la falsedad del resultado de esa implicación. Pondré un ejemplo. 
Sentencia de la Audiencia Provincial de Madrid (Sección 23.a) núm. 26/2002, de 21 de marzo

Se discute un recurso de una sentencia que consideró probado, oído el testimonio de dos agentes de la Guardia Civil, que el recurrente condujo bajo los efectos del alcohol, no se detuvo ante la señal de alto de los agentes y, tras ser perseguido unos minutos, intercambió la posición de conductor con la de su acompañante. El recurrente alegaba que no conducía él sino su acompañante y que hubo error en la apreciación de la prueba. La Audiencia coincide con el juez de primera instancia en creer más verosímil la versión de los agentes $\left(\mathrm{FJ} 1 .^{\circ}\right)$ :

[...] ante la contundencia de los hechos acreditados por su intervención, como infiere el mismo Juzgador, al destacar por reducción al absurdo, el hecho que el vehículo prosiguiera su marcha, pese a la orden de detención dada por los agentes, siendo así que iba conduciendo una persona sobria, en la versión del acusado.

Parece razonarse que si en efecto no conducía el recurrente sino su acompañante, ello implicaría que el coche se detuvo ante el alto de la Guardia Civil, porque los conductores sobrios se detienen al recibir el alto de la Guardia Civil; pero como el coche no se detuvo, resulta que esa hipótesis implica un resultado falso y conduce al absurdo, y por eso debe ser desestimada. El argumento, aunque defectuoso, se presenta como una reducción al absurdo?.

\subsubsection{Falsedad jurídica}

El resultado inaceptable que se confronta con la reducción al absurdo es a veces una afirmación claramente falsa sobre el derecho. Esta posibilidad está a medio camino, en un continuo difícil de compartimentar, entre las referencias a la falsedad fáctica $(\$ 1.3 .1)$ y a la incoherencia jurídica $(\$ 1.4)$. Porque si una afirmación es jurídicamente falsa lo será o bien porque es contraria a los hechos, o bien porque es incoherente con un conjunto aceptado de afirmaciones sobre el derecho. No obstante, con esa cautela en mente es viable singularizar esta modalidad de absurdo jurídico que consiste en implicar como verdadera una proposición nítidamente contraria al derecho ${ }^{10}$. En la falsedad fáctica la referencia típica son hechos del mundo susceptibles de verificación, mientras que en la falsedad jurídica la referencia típica son contenidos normativos. Éstos están muy expuestos a la interpretación, pero pueden ser suficientemente claros para fundamentar juicios de verdad o falsedad. Por esto mismo cabe distinguir también

9 El argumento es defectuoso porque la implicación que da por supuesta es discutible (pues cabe la posibilidad de que un conductor sobrio no se detenga ante el alto de la Guardia Civil), y además es precisamente lo que se discute (pues el recurrente alega que conducía alguien sobrio que no se detuvo), con lo cual el argumento incurre en petición de principio.

10 Distinta de la reducción al absurdo por falsedad jurídica es el argumento que combate una determinada tesis mostrando que se apoya en una falsedad. El argumento aquí no es la implicación de la tesis combatida, sino su falta de sustento. Por ejemplo, en la Sentencia del Tribunal Supremo (Civil) 5898/1997, de 6 de octubre de 1997, se dice que algunas de las peticiones del recurrente «no son de considerar pues se basan en argumento falso, cual es la falta de personalidad de la entidad sobre cuyo alcance el propio recurrente se contradice» $\left(\mathrm{FD} 5 .^{\circ}\right)$. 
entre negar una realidad jurídica que se tiene pacíficamente por verdadera (absurdo por falsedad) y negar una tesis jurídica que se desprende de prácticas incuestionadas (absurdo por incoherencia). Tal vez con un ejemplo se vea mejor este matiz.

Sentencia del Tribunal Superior de Justicia de Asturias (Sala de lo Social, Sección 1.`) núm. 613/2008, de 19 de marzo

Se desestima un recurso en el que un trabajador despedido por unas manifestaciones verbales sostenía que estaban protegidas por su libertad de expresión. La sentencia considera que el trabajador incumplió los deberes laborales de buena fe, diligencia y colaboración que impone el Estatuto de los Trabajadores, e incurrió en causa legal de despido. Y añade (FD 1. ${ }^{\circ}$ ):

De ello se infiere con toda facilidad la razón del fracaso del recurso que se examina ahora, aunque sea por el elemental método de reducción al absurdo, pues si, como el mismo sostiene, cualquier juicio, opinión o crítica vertida en cualquier lugar u ocasión y por cualquier medio estuviese amparada sin más por el derecho fundamental invocado, como comprendida en su legal contenido, quedarían vacías cuantas disposiciones castigan el exceso dañoso para los bienes ajenos jurídicamente protegidos y, desde luego, en referencia al objeto procesal, las causas de despido radicadas en ofensas o malos tratos de palabra o en mala fe contraria a los fines empresariales o al patrimonio económico y también moral o personal de los demás trabajadores y del empresario.

El argumento expuesto es sencillo: la hipótesis de que las opiniones o críticas realizadas por el trabajador están siempre protegidas por el derecho fundamental a la libertad de expresión debe rechazarse, porque implica que el derecho nunca pone límites a la libertad de expresión para proteger otros bienes, ni nunca permite al empresario despedir a un trabajador por causa de sus expresiones, lo cual es claramente falso. Se trata de una falsedad jurídica, porque resulta evidente que el derecho no ampara cualquier expresión, y por ello una hipótesis que conduce a esa conclusión inaceptable es absurda. Hay sin duda una incoherencia con el ordenamiento jurídico (pues la implicación que hace el recurso es incongruente con los principios del ordenamiento), pero más bien un conflicto directo. Y podría entenderse que hay una falsedad fáctica (pues hay de hecho legislación publicada que dispone consecuencias negativas para las expresiones ofensivas), pero requiere interpretación más que verificación.

\subsection{Absurdo por incoherencia}

He sugerido que, entendida en sentido amplio, la reducción al absurdo puede basarse en la relación de coherencia, que es un tipo de congruencia más débil que la consistencia lógica (no contradicción) y que la correspondencia con los hechos (no falsedad), pero más próximo a ellas que a la relación de utilidad, conveniencia o deseabilidad basada en las consecuencias. A mi juicio, circunscribir el argumento por reducción al absurdo a las versiones basadas en la inconsistencia, la falsedad o la opinión común (RESCHER, 2005; JANSEN, 2007), es excesivamente restrictivo. En su variante más empleada en el razonamiento jurídico, el argumento por reducción al absurdo muestra que la hipótesis cuestionada conduce a resultados claramente incongruentes 
con ideas, valores o principios característicos del contexto intelectual en el que ha de entenderse la hipótesis. La hipótesis se califica de absurda porque sus implicaciones son notoriamente incoherentes con presupuestos ideológicos sobre el sistema de referencia comúnmente asumidos; porque carece de sentido desde el punto de vista de ese sistema, en nuestro caso el ordenamiento jurídico. Puede ser difícil distinguir entre la incoherencia y la falsedad en relación con un sistema de referencia; pero lo que pretendo transmitir es que la reducción al absurdo puede funcionar también cuando la contradicción con aquél no es frontal y nítida (falsedad), sino difusa pero notoria.

Es una cuestión de interpretación, e indeterminada, cuáles son las exigencias básicas de la coherencia jurídica; y es una cuestión de grado cuándo se respetan. En todo caso, el uso jurídico de la reducción al absurdo suele hacer referencia a ideas muy difundidas y poco polémicas sobre los mínimos de racionalidad y de funcionalidad exigibles en el derecho, y a conflictos patentes con tales mínimos. Se asume que el ordenamiento jurídico tiene unas propiedades necesarias para cumplir su función y una unidad fundamental de contenido y de propósitos. Esta base ideológica se concreta en una serie de tesis sobre el derecho que actúan como premisas de contraste de cualquier hipótesis jurídica, por cuanto impiden mantener las que impliquen proposiciones contradictorias con ellas. Estas premisas jurídicas conciernen a diversos aspectos del derecho y admiten distintas clasificaciones. Aquí distinguiré tres tipos de coherencia del ordenamiento y de sus normas, así como su respectiva incoherencia, según se refieran al contenido $(\$ 1.4 .1)$, a la eficacia $(\$ 1.4 .2)$ o a los fines $(\mathbb{1} 1.4 .3)$. No son tipos necesariamente excluyentes, ni tampoco exhaustivos, sino sólo ilustrativos.

\subsubsection{Incoherencia con el contenido del ordenamiento y de sus normas}

El punto de vista jurídico típico considera inaceptable y absurda cualquier tesis sobre el contenido del derecho que no respeta en él una cierta armonía y unidad de criterio. Se asume que el ordenamiento jurídico es efectivamente un orden y posee una estructura sistemática que tiene que ver con la forma de producción y con el contenido material de sus normas. Este aspecto de la coherencia jurídica fundamenta diversas premisas que sirven de referencia para otras tantas reducciones al absurdo. Así, por ejemplo, se toma como absurda la interpretación que implica que dos normas del ordenamiento igualmente válidas y aplicables se contradicen entre sí; o que una norma se aparta de los principios explícitos o implícitos de otras normas, cuando puede interpretarse en armonía con ellos. Veamos una muestra.

\section{Sentencia del Tribunal Constitucional 194/2000, de 19 de julio}

Discute el significado de la expresión «correspondiente documento» en la Disposición adicional cuarta de la Ley 8/1989, de 13 de abril, de Tasas y Precios Públicos, que decía:

En las transmisiones onerosas por actos inter vivos de bienes y derechos que se realicen a partir de la entrada en vigor de la presente Ley, cuando el valor comprobado a efectos del Impuesto sobre Transmisiones Patrimoniales exceda del consignado por las partes en 
el correspondiente documento en más del 20 por 100 de éste y dicho exceso sea superior a 2.000.000 de pesetas, este último, sin perjuicio de la tributación que corresponda por el Impuesto citado, tendrá para el transmitente y para el adquirente las repercusiones tributarias de los incrementos patrimoniales derivados de transmisiones a título lucrativo.

El Abogado del Estado sostuvo que el «correspondiente documento» es la autoliquidación del impuesto de transmisiones patrimoniales (ITP). El Tribunal Constitucional discrepa, con el siguiente argumento (FJ 2. $\left.{ }^{\circ}\right)$ :

En primer lugar está la propia letra de la norma, que no habla de «autoliquidación», sino de «correspondiente documento». Pero, sobre todo, afirmar, como hace el Abogado del Estado, que ese «documento» es la autoliquidación en el ITP, implica sostener que el comportamiento infractor del adquirente - a saber, la determinación en su declaración del Impuesto sobre Transmisiones Patrimoniales de una base imponible inferior al valor real- puede tener trascendencia tributaria para el transmitente (el gravamen como ganancia patrimonial en el IRPF o en el Impuesto de Sociedades [...] de la diferencia entre el valor comprobado y el valor declarado), que, evidentemente, no es — no puede ser- responsable del eventual incumplimiento de las obligaciones tributarias de la persona con la que contrata, a saber, el adquirente.

En definitiva, por «correspondiente documento» hay que entender el documento, público o privado, en el que las partes contratantes plasman la transmisión. Cabe, desde luego, distorsionando la letra del precepto y obviando las consecuencias absurdas a las que conduce, hacer una distinta interpretación; ello, sin embargo, supondría una reconstrucción de la norma misma no explicitada debidamente en el texto legal impugnado y, por ende, la creación de una norma nueva, con la consiguiente asunción por el Tribunal Constitucional de una función de legislador positivo que constitucionalmente no le corresponde [...].

Es decir, para el Tribunal Constitucional el «correspondiente documento» es el que plasma el acuerdo de transmisión porque la hipótesis alternativa (según la cual es la autoliquidación del impuesto) tiene implicaciones absurdas. Y las implicaciones son absurdas porque resultaría algo ajeno a los principios y la lógica del ordenamiento, algo inaceptable desde el punto de vista jurídico; a saber: que la responsabilidad tributaria de quien transmite a otro un bien esté en función de los impuestos que eventualmente liquide el adquirente (porque nadie puede ser obligado a responder por actos de personas de las que no es responsable).

\subsubsection{Incoherencia con la eficacia del ordenamiento y de sus normas}

También resulta incoherente y absurdo, desde el punto de vista jurídico típico, privar de sentido al ordenamiento como medio de regulación de conductas. Si una hipótesis implica que alguna norma jurídica carece totalmente de función, implica un absurdo y debe abandonarse. Son derivaciones de esta idea, por ejemplo, que es absurda la interpretación jurídica que implica que el texto de una disposición legal no expresa su contenido; que una norma es totalmente superflua e inútil; o que carece de eficacia. Pondré algunos ejemplos.

Sentencia de la Audiencia Provincial de Las Palmas, de 20 de diciembre de 1993

El argumento que nos interesa aquí versa sobre la interpretación del art. 9.1 del Real Decreto-ley 2/1985, de 30 abril, de Medidas de Política Económica, que decía así: 
1. Los contratos de arrendamiento de viviendas o locales de negocio que se celebren a partir de la entrada en vigor del presente Real Decreto-ley tendrán la duración que libremente estipulen las partes contratantes, sin que les sea aplicable forzosamente el régimen de prórroga establecido por el art. 57 de la Ley de Arrendamientos Urbanos, Texto Refundido aprobado por Decreto 4104/1964, de 24 de diciembre, y sin perjuicio de la tácita reconducción prevista en el art. 1.566 del Código Civil.

Estaba claro que con la nueva regulación era admisible evitar la prórroga legal mediante pacto; pero la duda interpretativa era qué ocurría a falta de tal pacto. La prórroga legal no era «aplicable forzosamente», pero ¿era aplicable por defecto, cuando no hubo pacto en contrario? La sentencia contesta negativamente y aporta este razonamiento $\left(\mathrm{FD} 4^{\circ}{ }^{\circ}\right)$ :

La expresión: «...sin que sea aplicable forzosamente el régimen de prórroga establecido en el art. 57...», no implica que la prórroga legal sea un elemento natural del contrato, cuya existencia se presuma salvo pacto en contrario. Ello porque, pese a que no sea muy feliz la dicción legal, han de utilizarse los criterios hermenéuticos que recoge el art. 3.1. ${ }^{\circ}$ del Código Civil. Se ha de acudir a la interpretación sistemática no sólo a lo ya expresado sino al último inciso del art. 9.1. ${ }^{\circ}$ «...y sin perjuicio de la tácita reconducción prevista en el art. 1.566 del Código Civil». Esta mención a la tácita reconducción, de admitir la interpretación de que se mantiene en vigor el régimen de prórroga forzosa salvo pacto en contrario, no resultaría comprensible y conduciría a una argumentación ad absurdum.

Es decir, la sentencia rechaza una interpretación según la cual la prórroga legal seguía siendo aplicable a falta de pacto que la excluyese. La interpretación rechazada tenía sin duda apoyo en el texto, que al referirse a la aplicación de la prórroga legal a los nuevos contratos no dice «sin que les sea aplicable», sino «sin que les sea aplicable forzosamente», con lo cual habría que entender que sí es aplicable en alguna medida, aunque no contra la voluntad de las partes. Sin embargo, a juicio de la Audiencia, esta interpretación conduciría al absurdo de privar de sentido a la remisión expresa que hace el precepto a las reglas generales de la tácita reconducción. La idea es que si la prórroga legal forzosa se mantuviese por defecto, la tácita reconducción ya no tendría razón de ser y la referencia a ella en el artículo sería ininteligible y estaría vacía de contenido ${ }^{11}$. De aquí se sigue que esa hipótesis interpretativa es insostenible, ya que conduce a un resultado jurídicamente inadmisible, como es que un precepto legal carezca totalmente de efectos si alguna interpretación permite atribuírselos.

\section{Sentencia del Tribunal Supremo (Social) 2407/2007, de 27 de enero de 2009}

El objeto del proceso era un despido disciplinario declarado improcedente. El convenio colectivo de la empresa decía: «Declarado improcedente por la Jurisdicción Social el despido de un trabajador será éste el que opte entre readmisión o indemnización, excepto en los casos en que el despido se efectúe a consecuencia de ofensas verbales o físicas a personas que trabajan en la empresa, deslealtad, abuso de confianza o

11 Este razonamiento puede discutirse. La tácita reconducción puede tener razón de ser también con un sistema de prórroga legal, sobre todo cuando ésta puede excluirse por pacto. El precepto podría estar diciendo que el pacto de excluir la prórroga forzosa es admisible pero no puede afectar en ningún caso a la tácita reconducción, cuya regulación sí es aplicable forzosamente. Esta interpretación es acaso incorrecta, pero no absurda. 
fraude en las funciones desempeñadas, [etc.]». La empresa pretendía aplicar la excepción, porque había despedido al trabajador por una supuesta transgresión de la buena fe contractual que los sucesivos procedimientos judiciales consideraron inexistente. Se discute, entonces, si un despido es «a consecuencia de» las prácticas citadas en el convenio colectivo simplemente cuando así lo declara el empresario o, por el contrario, se requiere que el motivo se haya dado realmente según el parecer judicial. El Tribunal Supremo sostiene lo segundo, y razona así (FJ 2. ${ }^{\circ}$ ):

la interpretación que el recurso sostiene —otorgando los efectos discutidos a la simple acusación de la falta — conduciría al absurdo [argumento ad absurdum, de constante utilización por la Sala (...)] de que fácilmente pudiera burlarse la mejora atribuida por el Convenio Colectivo a los trabajadores, bastando para ello con la formal — gratuita— imputación de cualquiera de las causas de despido excluyentes del beneficio [ofensas, transgresión de la buena fe, drogadicción y riñas], en artificio incluso rechazable por contrario al art. 1.256 CC, que prohíbe dejar al arbitrio de una de las partes el cumplimiento de las obligaciones.

Según esto, la hipótesis de que el despido es «a consecuencia» de los motivos que exceptúan la obligación de readmitir si así lo declara el empresario implica que éste podría evitar la readmisión simplemente aduciendo esos motivos en el despido, y ello crea el absurdo de hacer disponible una obligación jurídica taxativa (la premisa de contraste aquí es que las obligaciones taxativas no están a disposición de los sujetos obligados); de manera que ha de abandonarse esa hipótesis a favor de una interpretación alternativa según la cual ha de darse «la realidad del hecho imputado» para que el despido sea «a consecuencia» de él ${ }^{12}$.

\section{Sentencia del Tribunal Supremo (Social, Sección 1. ${ }^{a}$ ) de 16 de octubre de 2006}

En este ejemplo se considera absurda una interpretación que hace que una acción expresamente permitida por la ley sea imposible de realizar. Se trataba de la posibilidad que prevé el art. 56 del Estatuto de los Trabajadores de evitar salarios de tramitación en caso de despido improcedente cuando la indemnización se deposita «en las cuarenta y ocho horas siguientes al despido». En el caso presente entre el despido y el depósito los juzgados estaban cerrados por ser días festivos (Semana Santa); y el Tribunal Supremo razona así (FD 2. ${ }^{\circ}$ ):

Obviamente si [la indemnización] se ha de depositar en el juzgado, es preciso que, en el momento que deba realizarse, exista la posibilidad material de hacerlo, por hallarse abiertas las dependencias del órgano judicial en las que el depósito deba realizarse. Es absurdo entender que el empresario no puede lograr la exención del pago de salarios de tramitación, porque — no estando disponible el órgano en que ha de realizarse- no pueda llevar a cabo el depósito que la Ley exige. [...] Y debemos rechazar cualquier interpretación que conduzca al absurdo. Es por ello que, siendo la actividad a realizar una actuación ante los juzgados, el plazo ha de ser considerado como plazo procesal, procediendo descontar los días inhábiles para su cómputo.

12 El problema obvio de esta interpretación es que si en efecto hubiese ocurrido el hecho que legalmente justifica el despido, éste ya no sería improcedente. El Tribunal Supremo sortea esta dificultad exigiendo que la realidad del motivo esté «básicamente acreditada pero no tenga entidad suficiente para justificar la decisión extintiva». Es una solución plausible para interpretar un precepto ambiguo, pero no es una solución obvia, lo cual indica quizás que la interpretación rival no es totalmente absurda. 


\subsubsection{Incoherencia con los fines del ordenamiento y de sus normas}

El punto de vista jurídico también considera incoherente con el ordenamiento jurídico, y absurda, cualquier hipótesis que impida que las normas jurídicas favorezcan los fines que las justifican. Como los fines de las normas jurídicas son muy variados y difusos, también lo son las ocasiones en las que se interpreta por este motivo que una conclusión jurídica es inaceptable o absurda. Puede tratarse de fines concretos de una norma determinada, producto de una política legislativa particular. O puede tratarse de fines genéricos que cabe atribuir al ordenamiento jurídico en su conjunto, por ser sus valores superiores, implícitos o explícitos. Por ejemplo, puede rechazarse una interpretación jurídica porque implica un resultado contrario a los fines de justicia, de promoción de la utilidad social y del bien común, de eficiencia, de seguridad, etc. Este motivo de incoherencia es muy amplio, y puede invitar a considerar absurdo cualquier resultado que a quien argumenta le parece irrazonable, contrario al sentido común o perjudicial. Veamos también aquí un ejemplo.

\section{Sentencia de la Audiencia Provincial de Islas Baleares (Sección 1.a) 30/2005,} de 14 de marzo de 2005

En esta sentencia puede verse un ejemplo de reducción al absurdo por referencia a lo que el decisor considera sensato y razonable. Se discute si un registro domiciliario autorizado por un juez por un presunto delito de tráfico de drogas se realizó correctamente. Entre los posibles motivos de nulidad alegados por el recurso estaría que la policía entró en el domicilio antes que la secretaria judicial. La Audiencia Provincial considera que este motivo debe desestimarse, y se apoya en este argumento (FD $3 .^{\circ}$ ):

Como declararon los testigos agentes de la Policía Nacional [...], la entrada en el domicilio registrado por parte de la Secretaria judicial tuvo lugar entre el grupo de agentes policiales, algunos de los cuales penetraron en la vivienda por delante de ella justamente por razón de su condición de funcionarios armados, como ocurre en la generalidad de los registros domiciliarios, y por razones de estricta seguridad. De manera que la tácita pretensión de los acusados de que el secretario judicial sea el primero en penetrar en la vivienda registrada, seguido de los policías judiciales, so pena de supuesta nulidad de dicha diligencia, debe ser rechazada simplemente por reducción al absurdo, debiendo recordarse que el art. 569 de la Ley de Enjuiciamiento Criminal exige en este tipo de diligencias la presencia del Secretario judicial exclusivamente en su calidad de fedatario público, sin necesidad ni obligación alguna de poner en riesgo su vida o su integridad física.

El argumento empleado es simple: la tesis según la cual un registro domiciliario es nulo si no lo inicia personalmente el secretario judicial debe rechazarse, porque implicaría que el secretario judicial tendría que asumir un riesgo para su vida o integridad física en muchos registros domiciliarios, lo cual es jurídicamente absurdo e inaceptable. Pero la razón por la que esta implicación es absurda (la premisa de contraste) hay que presumirla: porque es irrazonable y contrario al sentido común exigir al secretario judicial, cuya función y responsabilidad es dar fe pública, que asuma esos riesgos. Se toma aquí como punto de vista jurídico (fundadamente) el postulado de que el derecho persigue fines razonables por medios razonables, y de ahí se sigue que 
son inaceptables las tesis jurídicas que conducen a consecuencias incoherentes con esa razonabilidad en los fines y en los medios.

\section{PROBLEMÁTICA DE LA REDUCCIÓN AL ABSURDO EN LA ARGUMENTACIÓN JURÍDICA}

La argumentación por reducción al absurdo practicada en el razonamiento jurídico, en particular en la motivación de las decisiones jurídicas, tiene peculiaridades que suscitan problemas específicos. Abordaré seguidamente algunos de ellos.

\subsection{Forma lógica del argumento}

En los estudios sobre la argumentación jurídica, la reducción al absurdo suele clasificarse entre las formas de argumentos especiales ${ }^{13}$. Se trata de argumentos cuya forma lógica se reconoce con cierta facilidad y puede ser expresada como una inferencia válida si se explicitan y formulan adecuadamente todas las premisas.

Ahora bien, no es evidente cómo ha de formalizarse el argumento jurídico por reducción al absurdo. Según AlEXY [(1978) 1989: 270] un caso del argumento por reducción al absurdo se da cuando se rechaza una determinada interpretación (R') de una norma porque «lleva a resultados que se califican como inaceptables, absurdos, incomprensibles o con alguna otra expresión semejante»; en cuyo caso el argumento tendría esta estructura:

$$
\begin{array}{ll}
\text { 1. } & \mathrm{O} \rightarrow \mathrm{Z} . \\
\text { 2. } & \mathrm{R} \rightarrow \mathrm{Z} . \\
\text { 3. } & \neg \mathrm{R}^{\prime} .
\end{array}
$$

En la exposición de ALEXY, la reducción al absurdo parte de una prescripción —el estado $\mathrm{Z}$ está prohibido $(\mathrm{O} \neg \mathrm{Z})$ — y concluye una descripción $(\neg \mathrm{R}$ '). La conclusión del argumento formalizado por Alexy no es que la interpretación (R') que lleva al resultado prohibido $(\mathrm{Z})$ está prohibida (O $\neg$ R'), sino que no es verdadera o no es válida $\left(\neg R^{\prime}\right)$. Esto es chocante, y de hecho la prohibición ( $\mathrm{C} \neg \mathrm{R}$ ') es la conclusión que subyace (ver AlEXY, [1978] 1989: 233). Sin embargo un razonamiento que combinase enunciados deónticos $(\mathrm{O} \neg \mathrm{Z})$ y fácticos $\left(\mathrm{R}^{\prime} \rightarrow \mathrm{Z}\right)$ para obtener otro enunciado deóntico $\left(\mathrm{O} \neg \mathrm{R}^{\prime}\right)$ da lugar a paradojas (vid. ZuLETA, 2005: 77). La formalización de la reducción al absurdo tomando como punto de partida una prescripción requiere la lógica deóntica y acarrea problemas.

Las dificultades expuestas se evitan tratando la reducción al absurdo como un argumento con un punto de partida descriptivo. Así lo entienden, además, recientes análisis del argumento (KLOOSTERHUIS, 2007; JAnSEN, 2007). Sigo aquí este punto de vista.

13 Klug [1982], 1990: 139; Alexy [1978] 1989: 266; GASCÓn y GARCÍA FigUerOA, 2005: 200. En cambio TARELlo (1980: 369) incluye el «argumento apagógico (o ab absurdo o reductio ad absurdum o «hipótesis del legislador racional»)» junto con los demás argumentos de la interpretación. EzQUIAGA (1994) lo clasifica entre los argumentos «sistemáticos», distintos de los «interpretativos». Para Asís (1998: 75), es un criterio de justificación que interviene en el respaldo de algunas reglas jurídicas. 
De este modo, por ejemplo, en lugar de « $\mathrm{Z}$ está prohibido» $(\mathrm{O} \neg \mathrm{Z})$ la premisa es $« \mathrm{Z}$ es falso» $(\neg Z)$. En esta solución las normas jurídicas se representan como enunciados descriptivos y su contenido prescriptivo se reconduce a una norma extrajurídica que obliga a actuar conforme a la realidad descrita por el derecho. No sostengo que ésta sea la manera adecuada de representar las normas jurídicas, sino tan sólo que es una estrategia útil para analizar la reducción al absurdo en su uso jurídico. Se trata de ver el derecho como un conjunto de instrucciones, semejantes a las de un juego, de modo que « $\neg Z$ » significaría algo así como «Según el derecho (o las reglas del juego), $Z$ no es verdadero (o válido)»; o bien: «Z es contrario a derecho»; o también: «Para seguir el derecho (o el juego) ha de rechazarse $Z \gg$. El argumento se conduciría así:

$$
\begin{array}{ll}
\text { 1. } & \neg \mathrm{Z} . \\
\text { 2. } & \mathrm{R} \mathrm{R}^{\prime} \rightarrow \mathrm{Z} . \\
\text { 3. } \neg \mathrm{R}^{\prime} .
\end{array}
$$

El argumento viene a ser una versión extendida de la regla de inferencia modus tollens (WESTON, 1992: 55). El modus tollens parte de un condicional y de la negación de su consecuente y de ahí deduce la negación del antecedente. La demostración por reducción al absurdo opera según ese mismo esquema. Muestra que la verdad de una cierta hipótesis A implica la verdad de otra B, la cual sin embargo se considera falsa $(\neg \mathrm{B})$, y de todo ello deduce que la primera hipótesis también es falsa $(\neg \mathrm{A})$. Es decir:

$$
\begin{aligned}
& A \rightarrow B \\
& \neg \mathrm{B} \\
& \neg \mathrm{A}
\end{aligned}
$$

\subsection{La justificación jurídica por reducción al absurdo}

Una decisión o conclusión jurídica se justifica de modo concluyente mediante una reducción al absurdo cuando ésta o bien se construye explícitamente como una demostración lógica a partir de premisas verdaderas o suficientemente fundadas, o bien puede reconstruirse así pues son inferencias correctas a partir de premisas implícitas verdaderas o fundadas. En otro caso, el argumento puede ser más o menos persuasivo, pero no basta para justificar la conclusión. La deducción por reducción al absurdo demuestra una tesis probando que al negarla se incurre en contradicción con una tesis previamente aceptada; y la justificación de la conclusión requiere no sólo que el argumento tenga lógica interna, sino también que las premisas que emplea sean sólidas, incluida la tesis previamente aceptada que se considera absurdo negar y que sirve de premisa de contraste. Considérese el siguiente ejemplo.

Auto del Tribunal Constitucional (Sala 2. ${ }^{a}$ ) 274/1983, de 8 de junio

Una persona que había sido eliminada en unas oposiciones para obtener una plaza de auxiliar en un ayuntamiento y cuyos recursos judiciales habían sido desestimados recurría en amparo por vulneración del derecho fundamental a la tutela judicial efecti- 
va. El Auto inadmite el recurso por entender que esta tutela no se extiende a la discrecionalidad técnica; y motiva así su decisión (FJ único):

La primera de las razones que aduce en favor de su pretensión de amparo la recurrente consiste en la supuestamente necesaria fiscalización por parte de los jueces y Tribunales del poder judicial de «cualquier actuación administrativa» incluso de aquellas consistentes en decisiones de órganos competentes para resolver oposiciones en función de valoraciones técnicas, como ocurrió en el caso en que ella opositó y no fue propuesta por el Tribunal juzgador. Ahora bien, tal afirmación carece de fundamento, pues aunque los Tribunales de la jurisdicción contencioso-administrativa son ciertamente competentes para enjuiciar los aspectos jurídicos de la actuación del órgano juzgador de la oposición, en modo alguno pueden sustituir o corregir a éste en lo que su valoración tiene de apreciación técnica, pues de admitirse la hipótesis que la recurrente sostiene tendrían que constituirse en cada caso en fiscalizadores de cada Tribunal con parámetros no jurídicos, sino pertenecientes en cada ocasión a una técnica diversa, esto es, la concerniente a la materia cuyos conocimientos se exigiera a los opositores, y tal supuesto es absurdo no sólo porque humanamente implicaría la omnisciencia de los órganos judiciales, sino porque éstos están llamados a resolver problemas jurídicos en términos jurídicos y nada más. Por ese lado, la demanda carece manifiestamente de contenido constitucional.

El razonamiento del Tribunal Constitucional sigue estos pasos:

1. Sólo es competente jurídicamente para fiscalizar las decisiones técnicas administrativas sobre una materia quien es competente técnicamente en esa materia ${ }^{14}$ (la sentencia asume esta tesis como una premisa que es absurdo negar).

2. Los órganos judiciales no son competentes técnicamente en todas las materias que son objeto de decisiones técnicas administrativas (también esta tesis se acepta como premisa que es absurdo negar).

3. Supongamos esta hipótesis (según propone la recurrente): Los órganos judiciales son competentes jurídicamente para fiscalizar las decisiones técnicas administrativas sobre cualquier materia.

4. Los órganos judiciales son competentes técnicamente en todas las materias que son objeto de decisiones técnicas administrativas (se deduce de 1 y 3 ).

5. Los órganos judiciales son y no son competentes técnicamente en todas las materias que son objeto de decisiones técnicas administrativas (tesis absurda, por contradictoria, que se deduce de la combinación de 2 y 4 ).

6. Los órganos judiciales no son competentes jurídicamente para fiscalizar las decisiones técnicas administrativas sobre cualquier materia (conclusión que se sigue de lo anterior, al negar la hipótesis 3 por conducir al absurdo).

Aquí el Tribunal Constitucional refuta una hipótesis (3) mostrando que combinada con premisas aceptadas ( 1 y 2 ) tiene implicaciones contradictorias, y concluye así la tesis opuesta (6). El argumento es válido desde el punto de vista lógico, porque sus pasos son inferencias correctas. Sin embargo el argumento sólo proporcionará una justificación suficiente de la conclusión si sus premisas son sólidas, lo cual es el caso de

${ }_{14} \mathrm{El}$ argumento del Tribunal Constitucional se aprovecha de la ambigüedad de la expresión ser competente, que significa tanto tener capacidad técnica como tener capacidad jurídica. Cuando dice que «los Tribunales de la jurisdicción contencioso-administrativa son ciertamente competentes para enjuiciar los aspectos jurídicos», se refiere seguramente a la competencia jurídica, pero su argumento pretende asociar ésta a la competencia técnica. Aquí supondré que el argumento versa sobre la competencia jurídica de los tribunales, y que el Tribunal asume como premisa que sin cierta competencia técnica no hay competencia jurídica. 
la segunda (sí parece absurdo negarla), pero no en cambio de la primera premisa, que es inverosímil ${ }^{15}$.

\subsection{La motivación de las decisiones jurídicas por reducción al absurdo}

El recurso a la reducción al absurdo es a menudo en la motivación de las decisiones jurídicas sólo un refuerzo, más o menos retórico o pragmático, de una justificación directa. No obstante, en ocasiones la reducción al absurdo se presenta como un argumento suficiente para la motivación. El siguiente Auto es expresivo al respecto.

\section{Auto del Tribunal Supremo (Civil, Sección 1. ${ }^{a}$ ), de 18 de abril de 2008}

Se discutía la interpretación del art. 219 de la Ley Orgánica del Poder Judicial, que como 16. ${ }^{a}$ causa de abstención y recusación incluye «haber ocupado el juez o magistrado cargo público o administrativo con ocasión del cual haya podido tener conocimiento del objeto del litigio y formar criterio en detrimento de la debida imparcialidad [...]». El Tribunal toma en consideración una posible lectura según la cual un juez ha de abstenerse de intervenir en cualquier litigio que trate de una materia de la que ya se había ocupado antes y sobre la que ya tiene una opinión formada, con el fin de preservar su imparcialidad. Al Tribunal Supremo le parece que esta interpretación aboca a un resultado absurdo y es insostenible (FD 2. ${ }^{\circ}$ ):

La causa 16. ${ }^{a}$ del art. 219 LOPJ no es aplicable al criterio jurídico que los jueces hayan manifestado al resolver los asuntos sometidos a su decisión. De mantenerse una interpretación distinta se produciría el absurdo de que los jueces sólo podrían conocer del mismo tema jurídico una única vez, pues de volverse a plantear, como ya expuso con anterioridad un criterio, le estaría vedado intervenir, por lo que tendría que abstenerse. Y las conclusiones que llevan al absurdo no pueden mantenerse en derecho (Sentencias de 21 de noviembre de 1994 y 28 de febrero de 1996), conforme al principio general reconocido por la jurisprudencia de que debe rechazarse toda interpretación e inteligencia que conduzca al absurdo (Sentencia de 9 de junio de 1956).

\subsection{Uso y abuso del calificativo «absurdo»}

En los comentarios sobre el uso jurídico de la reducción al absurdo es común destacar que lo que se toma como consecuencia absurda no lo es siempre de modo evidente para cualquiera, sino que a menudo es discutible y discutido; y que cuando el absurdo es evidente no hay necesidad de señalarlo. Se dice, entonces, que el argumen-

15 La tesis de que sólo tiene competencia jurídica para enjuiciar un hecho quien tiene cierta competencia técnica sobre la materia es extraña a la realidad del derecho. Los jueces y tribunales son competentes para fiscalizar conductas en materias sobre las que suelen carecer de conocimiento técnico: negligencia médica, falsedades contables, trastornos de la personalidad, etc. A menudo a los órganos judiciales se les exige enjuiciar materias no jurídicas y la única competencia extrajurídica que se espera de ellos es la habilidad para obtener la información técnica relevante de los peritos y expertos y, en su caso, para discriminar entre ellos cuando discrepan. 
to es o bien problemático (cuando hay desacuerdo sobre lo que es absurdo) o inútil (cuando hay acuerdo) ${ }^{16}$.

Este supuesto inconveniente del uso jurídico de la reducción al absurdo - $-\mathrm{o}$ es problemático o es inútil— no es baladí, pero tampoco debe exagerarse. De un lado, los desacuerdos sobre lo que es absurdo no son probablemente tan abundantes como parecen creer los críticos. Una cosa es lo que se declara o pretende en una controversia jurídica y otra lo que se cree verdaderamente. Cuando una decisión jurídica afirma que cierto resultado es absurdo, probablemente lo es para cualquiera, aunque ciertamente haya muchas excepciones. De otro lado, el consenso sobre lo que es absurdo no hace inútil o irrelevante el argumento. Por lo pronto, no es del todo cierto que nunca se hagan propuestas claramente absurdas ${ }^{17}$. Además, sobre todo, el argumento por reducción al absurdo puede ser lo suficientemente complejo como para mostrar que una hipótesis en apariencia verosímil conduce, tras un cierto número de pasos lógicos, a una conclusión inesperada e inaceptable.

Ahora bien, no cabe duda de que la reducción al absurdo es a veces sólo un recurso retórico, y puede dar lugar a un tipo de falacia que consiste en utilizar un lenguaje cargado o emotivo para reforzar la tesis que se defiende o para desacreditar la tesis opuesta ${ }^{18}$. Cuando el argumento por reducción al absurdo carece de una forma lógica reconocible o no puede reconstruirse como un argumento lógico, es muy posible que sea un argumento emotivo y falaz. El uso retórico de la invocación del absurdo es fácilmente explicable, pues la norma o interpretación que acaba siendo percibida como absurda será inevitablemente «derrotada» ${ }^{19}$.

\subsection{Interpretación e ideología en el absurdo por incoherencia}

En la argumentación jurídica, las versiones de la reducción al absurdo basadas en la inconsistencia o la falsedad se construyen con premisas cuya solidez no suele

16 Según TARELlo (1980: 369) «el “absurdo” es una noción históricamente relativa y mutable» y raramente tiene objetividad social; pero cuando en un área sociocultural todos consideran absurda una norma a nadie se le ocurre interpretarla en ese sentido. GUASTINI [(1996), 1999: 218] recoge la misma idea: «La percepción de qué es absurdo y qué es, en cambio, razonable, es algo absolutamente subjetivo y, por tanto, siempre controvertible. En los raros casos en que una determinada interpretación aparece como “obviamente” absurda, esto es, sentida como absurda por la generalidad de los intérpretes en un contexto histórico (social, cultural, etc.) determinado, el argumento en cuestión resulta totalmente inútil, ya que sirve para excluir una interpretación que nunca nadie soñaría proponer». En el mismo sentido, GASCÓN y GARCÍA FIGUEROA (2005: 206).

17 La Sentencia del Tribunal Supremo (Civil, Sección 1.a), 211/2000, de 28 de febrero de 2000, resuelve un curioso caso en el que alguien que había visto desestimado un recurso de nulidad de actuaciones en un proceso, con condena en costas, impugnaba la tasación de costas porque las actuaciones eran nulas según había sostenido en su recurso. La sentencia subraya el carácter absurdo de la pretensión.

18 Hay diversos modos de argumentación falaz que aprovecha las emociones para desacreditar una tesis sin aportar razones, y calificarla sin más de absurda es uno de ellos. Otros son ridiculizar la tesis adversa o asociarle consecuencias indeseables. También sembrar dudas sobre quien la sostiene o sobre la sensatez de sostenerla, lo cual se conoce como envenenar el pozo o descalificar la fuente [WESTON (1992: 87) 2006: 129]. Se comete esta falacia cuando se argumenta así: «Ninguna persona sensata piensa que...» (el ejemplo es de WESTON, 1992: 87). No hay apenas distancia entre ese modo de argumentar y este otro: «Es absurdo sostener que...».

19 Escribe GARCía Amado (2010: 197): «Las normas “positivas” pueden y deben ser “derrotadas” cuando conducen para un caso a resultados que la generalidad de los ciudadanos puede tener por absurdos, en cuanto que opuestos a dichas evidencias generalmente admitidas. De ahí la enorme potencia del argumento al absurdo como límite a las aplicaciones lógica o semánticamente posibles de las normas "positivas”». 
cuestionarse, y por ello se considera que si el argumento es correcto su conclusión resulta probada. En cambio, las versiones basadas en la coherencia son más conflictivas, porque sus premisas son tesis interpretativas, siempre polémicas, sobre lo que es o no congruente con el ordenamiento jurídico. Algunos autores alertan contra la utilización de la reducción al absurdo en estas versiones más débiles ${ }^{20}$. Pero denunciar una incoherencia fundamental con el ordenamiento puede bastar para construir un argumento jurídico justificatorio, porque en el derecho la justificación es un asunto de racionalidad y razonabilidad y no (solo) de lógica o de verdad ${ }^{21}$.

Las tesis sobre la coherencia jurídica que operan como premisas (usualmente tácitas) de las reducciones al absurdo se refieren ante todo al contenido normativo, del que se supone cierta homogeneidad en orientación y principios; pero también a ideas fundamentales sobre las funciones y fines del derecho (supra $\$ 1.4$ ). Vista así, la noción de coherencia ejemplifica y a la vez resume un conjunto de propiedades que los juristas comúnmente asocian a los ordenamientos jurídicos y emplean como guías para interpretarlos. La recepción de estos presupuestos metodológicos o ideas regulativas es explicada otras veces como la aceptación del postulado de que el legislador es racional, o al menos razonable. Sin duda, la aceptación de este postulado tiene mucho que ver con el uso habitual de la reducción al absurdo como argumento jurídico ${ }^{22}$. Con todo, esta atribución debe tomarse con cautela, pues los juristas son conscientes de que el derecho es imperfecto y no todo defecto les resulta absurdo. A los juristas no les resulta absurda cualquier contradicción, falsedad, incoherencia o disfunción del ordenamiento jurídico y de las interpretaciones de éste, sino sólo las graves y manifiestas. Ante ciertas irracionalidades del ordenamiento tenidas por menores o inevitables (por ejemplo la existencia de normas superfluas, confusas, ambiguas o con fines incompatibles con los de otras normas), la interpretación jurídica tratará de corregirlas; pero no se argumenta que la disfunción es inexistente por absurda, ni tampoco que es absurda la interpretación que no trata de corregir la disfunción sino que se aprovecha de ella. Es difícil ser más preciso, porque es una cuestión de grado y de apreciación cambiante cuáles son las incoherencias menores a las que los juristas se resignan y cuáles las incoherencias graves que les resultan inadmisibles.

20 Por ejemplo, según APPIAH (2003: 52), «es importante en una prueba por reductio que la consecuencia que extraemos no solo nos resulte absurda, sino que sea efectivamente falsa»; $y$ «hemos de ser muy cuidadosos con la reducción ad absurdum como forma de argumento. Esto se debe a que no siempre está claro que lo que tomamos como absurdo realmente es falso».

21 Dicen STELmach y BROzeK (2006: 115): «Al probar que el enunciado no-A es falso, probamos por medio de la ley de la doble negación que el enunciado A es verdadero. En un discurso práctico (jurídico), sin embargo, no probamos la verdad, sino la racionalidad y la corrección. No obstante debemos proceder de modo similar. Podemos probar que la tesis A es racional o correcta probando que la tesis opuesta, es decir no-A, es absurda».

22 Sobre el «modelo dogmático del "legislador racional”», vid., por ejemplo, NiNO (1989: 86-101). EzQUIAGA (1994: 97) pone en relación la reducción al absurdo con el postulado del legislador racional: «En principio, y por el papel que cumple en relación con el legislador racional, el razonamiento ad absurdum no puede considerarse un argumento autónomo, sino un esquema ad excludendum del que se vale el postulado para rechazar, mientras se utiliza otro argumento interpreta[tivo], toda atribución de significado que implique poner en cuestión la imagen de racionalidad del legislador; cualquier interpretación que conduzca a resquebrajar alguno de los atributos que se predican del legislador racional será considerada absurda y rechazada». 


\subsection{Consecuencias y fines}

En los análisis del razonamiento jurídico es habitual tratar indistintamente el argumento por reducción al absurdo y otros argumentos consecuencialistas o teleológicos. La asociación es natural, pero en rigor se trata de una confusión. En ambos casos hay un punto de partida de cuya negación se obtiene una premisa hipotética, la cual es rechazada por las consecuencias que supuestamente conlleva. La diferencia estriba, según JANSEN (2007: 258), en que en el argumento por reducción al absurdo las consecuencias son implicadas o bien lógicamente o bien causalmente a partir de una premisa descriptiva imaginaria; mientras que el argumento consecuencialista apunta hacia una cadena causal real con un punto de partida prescriptivo. La distinción es sutil, pero relevante. El argumento por reducción al absurdo tiene que ver con las consecuencias lógicas de la hipótesis que se rechaza, y no tanto con sus consecuencias empíricas. La hipótesis se refuta con contradicciones, contraejemplos y analogías que rompen la cadena lógica; y el argumento mismo (la refutación de la hipótesis) se rebate con otras herramientas lógicas. En contraste, los argumentos consecuencialistas se basan en la causalidad empírica y se rebaten tanto con la lógica como con hechos. El argumento de la pendiente resbaladiza, por ejemplo, es consecuencialista pues está basado en una supuesta sucesión causal de eventos: se rechaza cierta solución en apariencia inocente porque previsiblemente dará lugar a resultados indeseables graves. Este modo de razonar es a menudo falaz y puede ser objetado por razones lógicas — por reducción al absurdo, precisamente-; pero si tiene fundamento empírico ha de refutarse con otros datos empíricos ${ }^{23}$.

La esencia de la reducción al absurdo es poner de manifiesto una implicación lógica que resulta problemática, y no tanto el resultado que debería evitarse y que hace problemática la implicación. El argumento es sistemático y no sustantivo ${ }^{24}$. En cambio, los argumentos consecuencialistas son sustantivos, pues el interés se sitúa en describir un mal y la probabilidad de que suceda. No obstante, cuando se rechaza una hipótesis porque tiene consecuencias indeseables o inconvenientes (y no falsas o ilógicas), es fácil que confluyan y se confundan la reducción al absurdo y la argumentación conse-

${ }^{23}$ Por ejemplo, hay quien sostiene que el consumo de hachís debe estar prohibido porque conduce al consumo y dependencia de drogas más peligrosas, ya que muchos adictos a éstas comenzaron consumiendo hachís. Podría pensarse que cabe aquí una reducción al absurdo: debe prohibirse el consumo de hachís, porque en otro caso se favorece la adicción a drogas duras, lo cual es absurdo. Sin embargo, este argumento no es una reducción al absurdo, sino una pendiente resbaladiza, porque la secuencia entre la hipótesis (se permite el consumo de hachís) y la consecuencia absurda (se facilita la adicción a drogas duras) no es lógica, sino causal. El argumento es consecuencialista, y un modo de contestarlo es negar los hechos en que se basa. La reducción al absurdo, en cambio, apunta a una secuencia lógica. Por ejemplo, puede objetarse así la anterior pendiente resbaladiza: si ha de prohibirse el consumo de hachís porque la mayoría de los adictos a drogas duras lo consumieron antes, también (lógicamente) habrá de prohibirse el consumo de leche por la misma razón, lo cual es absurdo. Este argumento no se contesta con hechos, sino negando su lógica interna o reformulando la pendiente resbaladiza.

${ }^{24}$ Según KloOsterhuis (2007: 73), si el argumento ad absurdum se define en sentido amplio, la inconsistencia se da «entre una interpretación específica y un efecto deseado que no puede considerarse como un principio indisputado del sistema jurídico. En estas situaciones, el argumentum ad absurdum es un argumento consistente en razones sustantivas y no un argumento sistemático». Pero la propuesta de KLOOSTERHUIS es diferenciar con cuidado el argumento sistemático y el sustantivo, y para ello es acaso preferible no llamar reducción al absurdo a un argumento consecuencialista sustantivo. 
cuencialista. Ciertamente, cuando se considera «absurdo» defender una interpretación jurídica que conduce a un resultado notoriamente indeseable, no importa demasiado si esta consecuencia es una implicación lógica o una probabilidad causal. Sin embargo, conceptualmente son argumentos distintos. No por decir que las consecuencias indeseables son «absurdas» estamos ante una reducción al absurdo. La clave de la reducción al absurdo no está en identificar un consenso sobre lo que es absolutamente rechazable, ni en alertar sobre un riesgo probable, sino en identificar un inconveniente lógico en el argumento rival. La reducción al absurdo tiene lugar cuando la consecuencia inaceptable se sigue lógica o sistemáticamente de la hipótesis cuestionada, y no cuando se sigue causalmente. En la teoría y en la práctica jurídicas se denomina a veces reducción al absurdo a un argumento que persigue evitar consecuencias «absurdas»; pero ésta sí es una utilización tal vez demasiado laxa de este nombre ${ }^{25}$.

El rechazo de una solución jurídica porque causaría consecuencias indeseables es una versión de la argumentación consecuencialista, que también se detecta en las decisiones jurídicas pero está menos presente en sus motivaciones. El uso de argumentos consecuencialistas como criterio de selección entre posibilidades jurídicas alternativas puede encontrar justificación (así MACCORMICK, 1994: 128-151). Otra cosa es el uso de argumentos consecuencialistas para corregir el derecho y desplazar la solución que resulta de éste. Para lograr este resultado puede ser útil argumentar que la respuesta del derecho es tan inconveniente que resulta absurda, y por tanto es inaplicable. Pero, como se dijo, no debe confundirse un argumento consecuencialista con una reducción al absurdo.

Ahora bien, sin duda es cierto que una respuesta jurídica cuyas consecuencias son claramente indeseables es sospechosa de no ser realmente la respuesta querida por el derecho, y es susceptible de ser rechazada con una reducción al absurdo. El derecho cumple ciertas funciones, tiene ciertos fines, posee un sentido o propósito; y las normas e interpretaciones que producen unos resultados abiertamente opuestos a tales funciones, fines y sentido no encajan en el derecho y han de quedar fuera de él. En los casos más flagrantes de consecuencias indeseables convergen los argumentos consecuencialistas y teleológicos con la reducción al absurdo basada en la coherencia (vid. supra

25 En contra, WACKE (2007: 453): «Entre este modo de argumentación [al que llama indistintamente deductio ad absurdum y reductio ad absurdum] y la de "considerar las consecuencias" existe a mi parecer sólo una diferencia de grado, pero no de raíz». Más adelante (p. 454) añade: «En mi opinión [y en contra de Uwe DiEDIRISCHEN (DIEDIRISCHEN, 1973)], entre la reductio ad absurdum en sentido estricto y la forma más bien popular de argumentar por la insostenibilidad de la opción contraria no existe una diferencia esencial». Y todavía más adelante (p. 455) coincide con quien incluye el argumento ad absurdum entre los argumentos de probabilidad. Sin embargo, como expliqué, hay una diferencia conceptual entre la reducción al absurdo y los argumentos que se basan en la probabilidad de consecuencias indeseables. Un ejemplo del propio WACKE ilustra esta diferencia. WACKE (2007: 456-457) pone como muestra del argumento que considera las consecuencias la interpretación que hace POMPONIO (Digesto 18,3,2-3) de una cláusula de la compraventa según la cual «Si ad diem pecunia soluta non sit, ut fundus inemptus sit» («si el precio no fuese pagado dentro del término, se tendrá por no comprado el fundo»). El argumento es que si se interpreta que la compraventa queda sin efecto siempre que el comprador no pague a tiempo, entonces el comprador no asumiría el riesgo de que el fundo comprado pierda valor antes del pago (por ejemplo, porque arda la casa), pues podría evitarlo con el impago; pero esto es absurdo, porque — dice POMPONIO-, la cláusula «se ha convenido en interés del vendedor» y no del comprador. A mi entender este argumento es una reducción al absurdo aunque aluda a unas consecuencias, porque su propósito no es advertir que la interpretación cuestionada causará resultados indeseables, sino mostrar que tiene implicaciones lógicas absurdas desde el punto de vista jurídico. POMPONIO no rechaza la interpretación rival por los perjuicios que causaría, sino porque carece de coherencia jurídica. 
\$1.4.3). El razonamiento teleológico se orienta hacia la consecución de fines y persigue la razonabilidad, mientras que el razonamiento lógico se orienta hacia la preservación de la consistencia y de la coherencia y persigue la racionalidad. Ambos son cruciales en la argumentación jurídica y siguen cursos independientes, aunque complementarios. Pero ambos coinciden en rechazar las soluciones radicalmente indeseables que, por serlo, se perciben como extrañas al sistema jurídico ${ }^{26}$. Por eso puede ser difícil precisar de qué estrategia argumentativa se trata, como en este ejemplo.

Sentencia del Tribunal Constitucional 24/1990, de 15 de febrero de 1990

Se discute la interpretación del art. 113.2 de la Ley Orgánica 5/1985, del Régimen Electoral General (antes de su modificación por Ley Orgánica 8/1991, de 13 de marzo). Según este precepto, en caso de apreciarse nulidad de la elección, el fallo de la sentencia será:

d) Nulidad de la elección celebrada y necesidad de efectuar nueva convocatoria en la circunscripción correspondiente o de proceder a una nueva elección cuando se trate de la del presidente de una Corporación Local, en ambos casos dentro del plazo de tres meses.

El Tribunal Constitucional se pronuncia sobre una decisión de 1989 del Tribunal Superior de Justicia de Murcia, que apreció irregularidades en dos mesas electorales y anuló las elecciones en toda la circunscripción de Murcia. El TC admite que la interpretación literal del precepto «da a entender que, decretada la nulidad, la nueva convocatoria ha de efectuarse en «la circunscripción correspondiente», porque la nulidad debe extenderse a toda la elección celebrada, y ello aunque el vicio invalidante y relevante esté constreñido a una sola mesa». Sin embargo entiende que una interpretación sistemática y finalista conduce a otra solución, y que el Tribunal debió limitar a las dos mesas afectadas la anulación y nueva convocatoria electoral. Y como refuerzo de su interpretación hace esta reducción al absurdo (FJ 6. ${ }^{\circ}$ ):

El salto cualitativo consistente en la anulación del resultado electoral en toda la circunscripción por vicios advertidos en una o dos mesas llevaría, de admitirse como correcto, a una vulnerabilidad del proceso electoral en manos de quienes malévolamente quisieran (acaso por disconformidad con el resultado electoral previsible o incluso con el sistema electoral y democrático) alterarlo en términos generales, pues la introducción fraudulenta de determinadas y aisladas irregularidades en Secciones escasas y concretas determinaría la anulación de las elecciones en una o varias circunscripciones, con los consiguientes perjuicios al interés general consistente en la credibilidad del sistema y en la protección del mismo frente a fáciles y perturbadores abusos, lo que constituye un bien jurídico al que una interpretación de la legalidad electoral ex Constitutione no puede ser ajena.

Esto es, a juicio del Tribunal Constitucional la interpretación del TSJ de Murcia, apegada al texto de la ley, debe ser rechazada porque conlleva que alguien podría anular las elecciones en una o más circunscripciones electorales simplemente provocando la nulidad de la elección en una o unas pocas mesas electorales. Y esta consecuencia es absurda e inaceptable desde el punto de vista jurídico por ser contraria al interés

26 Incluso puede verse la reducción al absurdo, siguiendo a SARTOR (2005: 161), como un modo de «atajar la complejidad del razonamiento teleológico» cuando «una sola consecuencia de una decisión es tan perjudicial que será improbable que pueda ser compensada por los efectos ventajosos de esa misma decisión». 
general en mantener un sistema electoral creíble y efectivo, lo cual es tanto un efecto perjudicial como una implicación incoherente ${ }^{27}$.

\subsection{El supuesto sentido corrector de la reducción al absurdo}

La reducción al absurdo puede tener un efecto corrector en el ordenamiento jurídico, cuando con ella se defienden interpretaciones de las normas que se apartan de su sentido más evidente. En efecto, el argumento busca a veces evidenciar los resultados absurdos a los que conduce la interpretación más inmediata o literal de la norma, con el fin de apoyar una interpretación alternativa y evolutiva. No obstante, por sí mismo el argumento ad absurdum no es necesariamente de índole correctora y opuesto al significado literal, contra lo que sugiere GUASTINI [(1996) 1999: 218]. En ocasiones el argumento protege la interpretación literal frente a propuestas alternativas que tienen implicaciones inaceptables, como ilustra el ejemplo que sigue. Es más, a menudo lo que se considera inaceptable es precisamente «ignorar o desfigurar el sentido de los enunciados legales meridianos», en frase del Tribunal Constitucional (Sentencia 22/1985, de 15 de febrero) ${ }^{28}$.

\section{Sentencia del Tribunal Supremo (Civil) 607/2006, de 9 de junio de 2006}

Se discute la interpretación del art. 132, caso $2 .^{\circ}$, de la Ley Hipotecaria, Texto Refundido aprobado por Decreto de 8 de febrero de 1947, en su redacción vigente en 1996 (ya modificada), relativo al procedimiento sumario de ejecución hipotecaria. El art. 132 admite la suspensión de dicho procedimiento en ciertos casos:

2. ${ }^{\circ}$ Si se interpusiere una tercería de dominio, acompañando, inexcusablemente con ella, título de propiedad de la finca de que se trate, inscrito a favor del tercerista o de su causante, con fecha anterior a la inscripción del crédito del actor, y certificación de no aparecer extinguido ni cancelado en el Registro el asiento de dominio a favor del tercerista.

La duda estribaba en si lo que había de tener fecha anterior a la inscripción del crédito era la inscripción del título de propiedad del tercerista o el título de propiedad mismo. El Tribunal Supremo opta por la segunda interpretación, y dice en su sentencia $\left(\mathrm{FD} 3 .^{\circ}\right)$ :

27 Cabe añadir que el TC aprovecha a favor de su interpretación la ambigüedad sintáctica de la expresión legal «en la circunscripción correspondiente»: «Tal interpretación del 113.2.d) puede darse y debe darse, entendiendo, sin forzar los términos literales y a la luz de lo hasta aquí expuesto, que cuando allí se habla de nueva convocatoria "en la circunscripción" se puede tratar restrictivamente de solo en dos o varias y determinadas mesas "en la circunscripción”, si en ellas y sólo en ellas se creyó advertir la existencia de irregularidades relevantes». Lo que según esto dice el precepto es que al anular la elección en una mesa se debe convocar una nueva elección en esa circunscripción y no en otra distinta. Esta interpretación salva la literalidad del precepto, pero es a su vez susceptible de una reducción al absurdo, porque implica que si el precepto no existiese podría convocarse la nueva elección en una circunscripción no afectada por la nulidad, lo cual es sin duda absurdo.

28 Tal vez la asociación entre argumento ad absurdum e interpretación correctora se deba a una asociación previa, ya comentada, entre el argumento ad absurdum y el razonamiento teleológico y consecuencialista. Así lo ve FETERIS (2009): «La argumentación teleológica-objetiva es a menudo empleada para corregir una regla prima facie clara si una interpretación literal conduciría a un resultado absurdo o irrazonable. Aquí la argumentación teleológica-objetiva forma parte de una argumentación referida a consecuencias absurdas (argumentum ad absurdum) o de una argumentación con base en la justicia». 
Conforme al elemento gramatical, la interpretación debe hacerse estimando las dos comas como un paréntesis, de esta forma: ...título de propiedad de la finca de que se trate (inscrito a favor del tercerista o de su causante) con fecha anterior a la inscripción del crédito del actor... (el que lo fue del procedimiento del art. 131). Lo cual se corresponde a la conceptuación y función de toda tercería, por lo que conduciría a una interpretación —aquí entra el elemento lógico, espíritu de la Ley-ad absurdum si se entendiera que el título debe estar inscrito antes de la constitución (por la inscripción) de la hipoteca; si lo estuviere, no sería posible inscribir tal hipoteca. Los autores que han estudiado el tema han advertido la dificultad de aplicar tal norma; no es dificultad, es absurda si se interpreta como si exigiera que el título de propiedad del tercerista [estuviese] inscrito con fecha anterior a la inscripción del crédito hipotecario; el título debe ser de fecha anterior, sin duda y debe estar inscrito, para obtener protección registral, pero no inscrito antes de la hipoteca. Con esta interpretación, esta Sala cumple lo previsto en el art. 1.6 del Código Civil al complementar el ordenamiento jurídico. La parte demandada y recurrida en casación cita una antigua sentencia, de 15 de diciembre de 1927 que parece afirmar lo contrario; aparte de que una sola sentencia no forma jurisprudencia, no es exactamente así: no se plantea el tema de la interpretación, sino que simplemente parte de la aparente exigencia de inscripción con anterioridad a la hipoteca.

De esta manera, el Tribunal Supremo defiende con una reducción al absurdo una interpretación muy apegada al texto. La ley dice: «título de propiedad de la finca de que se trate, inscrito a favor del tercerista o de su causante, con fecha anterior a la inscripción del crédito del actor». Como se ve, al Tribunal Supremo le parece absurdo que se interprete el texto prescindiendo de las comas, como si dijese título de propiedad a favor del tercerista inscrito con fecha anterior a la inscripción del crédito. Su tesis es que ha de interpretarse como título de propiedad (inscrito a favor del tercerista) con fecha anterior a la inscripción del crédito; es decir, como titulo de propiedad con fecha anterior a la inscripción del crédito e inscrito a favor del tercerista. La primera interpretación corrige el sentido literal del texto al privar de función a las comas. Al Tribunal Supremo el resultado le parece absurdo, porque si la propiedad del tercero estuviese inscrita al ir a inscribir el crédito y la hipoteca, éstos ya no se hubiesen podido inscribir. Si la hipoteca se pudo constituir sin intervención del propietario tuvo que ser porque su propiedad no estaba inscrita. Según esto, la Ley Hipotecaria le exigía al tercero que su propiedad estuviese inscrita para poder suspender la ejecución de la hipoteca, pero no le exigía que la inscripción fuese anterior a la propia hipoteca ${ }^{29}$.

29 Sin embargo, la interpretación que el Tribunal Supremo considera absurda no lo es tanto. Su argumento parece dar por sentado que las inscripciones del título de propiedad y del crédito hipotecario a las que se refiere el artículo comentado son ambas en el mismo Registro de la Propiedad. En este supuesto, es efectivamente inviable que pueda inscribirse una hipoteca sobre una finca sin que intervenga quien en el propio Registro consta como su propietario. Ahora bien, el artículo podría referir la inscripción del título de propiedad a cualquier registro y no sólo al Registro de la Propiedad en el que se constituye la hipoteca. En este caso no sería absurdo exigir que el título de propiedad esté inscrito antes que la hipoteca, porque si la inscripción previa se hizo en un registro distinto de aquel donde se va a constituir la hipoteca, ésta es perfectamente posible. De hecho, la redacción actual del precepto equivalente corrobora esta interpretación. El art. 696.1 de la Ley 1/2007, de 7 de enero, de Enjuiciamiento Civil, sobre los procedimientos de ejecución de bienes hipotecados, dice así: «1. Para que pueda admitirse la tercería de dominio en los procedimientos a que se refiere este capítulo, deberá acompañarse a la demanda título de propiedad de fecha fehaciente anterior a la de constitución de la garantía. Si se tratare de bienes cuyo dominio fuere susceptible de inscripción en algún Registro, dicho título habrá de estar inscrito a favor del tercerista o de su causante con fecha anterior a la de inscripción de la garantía, lo que se acreditará mediante certificación registral expresiva de la inscripción del título del tercerista o de su causante y certificación de no aparecer extinguido ni cancelado en el Registro el asiento de dominio correspondiente». 


\subsection{Absurdo implícito y reconstrucción lógica}

En la deducción por reducción al absurdo, el absurdo o contradicción surge cuando el argumento conduce a un resultado opuesto a una tesis previamente asumida. Para que la deducción sea válida, esa tesis de contraste ya asumida ha de estar presente en el argumento como una premisa o ser una consecuencia lógica de las premisas. Sin embargo, lo habitual en los razonamientos por reducción al absurdo que se plasman en las motivaciones de las decisiones jurídicas es que la tesis de contraste no se explicite ni sea deducible de premisas explícitas, y por ello estos razonamientos no suelen tener forma de demostración lógica ni pretenden tenerla. Más bien se presentan como argumentos materiales o pragmáticos a favor de una determinada decisión ${ }^{30}$. Se quiere que la justificación resulte convincente, pero no por su rigor lógico, sino por basarse en el sentido común o en el sentido jurídico más elemental, y así se pretende dar a la tesis defendida un carácter autoevidente e incuestionable. Ahora bien, para que el argumento sea correcto ha de haber una premisa que entra en conflicto con las implicaciones de la hipótesis rechazada (la alternativa de la defendida). Esta premisa no puede ser un producto obtenido a posteriori en el razonamiento ad absurdum, sino que es precisamente su presupuesto. Pero entonces siempre es posible utilizar la premisa de contraste en argumentos directos, que pueden ser más sencillos y eficaces. Veamos un ejemplo.

\section{Sentencia de la Audiencia Provincial de A Coruña (Sección 5. a) 179/2007,} de 20 de abril

La sentencia confirma una condena a reintegrar un pago de tributos que la empresa originalmente demandante, y aquí apelada, había hecho como sustituta. Entre otros razonamientos, la Audiencia Provincial apunta lo siguiente (FD 6. ${ }^{\circ}$ ):

Para concluir conviene señalar que la reducción al absurdo no es solo un método de demostración matemática, porque ningún análisis digno de la calificación de jurídico puede conducir al absurdo, como sucedería si a la apelada se le niega el acceso al proceso civil para pedir el reintegro de lo abonado como sustituto, porque, al no ser Administración pública, no dispone de otro medio para hacer efectivo su derecho.

Es decir, la Audiencia propone aplicar de modo intuitivo el argumento deductivo de la prueba por contradicción: se rechaza por contraria a derecho una interpretación que priva a un particular de su único medio para hacer efectivo su derecho, como es el acceso al proceso civil. Pero si se explicitan las premisas que emplea, el argumento que resulta es nítidamente deductivo. Expresado en lenguaje natural, el razonamiento quedaría aproximadamente así:

1. Todas las personas disponen de medios jurídicos (tienen medios jurídicos a su disposición) para hacer efectivos sus derechos (premisa).

${ }^{30}$ Sobre la diferencia entre las concepciones de la argumentación formal, material y pragmática, vid. ATIENZA, 2006. Como la invocación al absurdo en el razonamiento jurídico suele basarse en enunciados aceptados más que en enunciados verdaderos, se trataría principalmente de un tipo de argumentación pragmática (p. 92). No obstante, los elementos materiales y pragmáticos de la argumentación están con frecuencia imbricados (p. 257). 
2. Las personas que no son Administración Pública no disponen de medios jurídicos para hacer efectivos sus derechos cuando no tienen acceso al proceso civil (premisa).

3. Cierto sujeto $A$ es una persona y no es una Administración Pública (premisa). refutar).

4. Supongamos que $A$ no tiene acceso al proceso civil (hipótesis que se quiere

5. El sujeto $A$ es una persona (se deduce de 3, con la regla de eliminación de la conjunción).

6. Si $A$ es una persona, entonces $A$ dispone de medios jurídicos para hacer efectivos sus derechos (se deduce de 1 y 5 , con la regla de eliminación del cuantificador universal).

7. A dispone de medios jurídicos para hacer efectivos sus derechos (se deduce de 5 y 6, con la regla de eliminación del condicional).

8. Si $A$ es una persona y no es una Administración Pública, entonces $A$ no dispone de medios jurídicos para hacer efectivo sus derechos cuando no tiene acceso al proceso civil (se deduce de 2 y 3 , con la regla de eliminación del cuantificador universal).

9. A no dispone de medios jurídicos para hacer efectivos su derechos cuando no tiene acceso al proceso civil (se deduce de 3 y 8 , con la regla de eliminación del condicional).

10. A dispone de medios jurídicos para hacer efectivo sus derechos y no tiene acceso al proceso civil (se deduce de 4 y 7 , con la regla de inclusión de la conunción).

11. A dispone y no dispone de medios jurídicos para hacer efectivos sus derechos cuando no tiene acceso al proceso civil (se deduce de 9 y 10, con la regla de inclusión de la conjunción).

12. No es el caso que $A$ no tiene acceso al proceso civil (se deduce de 4-11 por reducción al absurdo, con la regla de inclusión de la negación).

13. A tiene acceso al proceso civil (conclusión; se deduce de 12, con la regla de eliminación de la negación).

En lenguaje formal ${ }^{31}$ :

$$
\begin{aligned}
& \text {-1. } \forall \mathrm{x}(\mathrm{Px} \rightarrow \mathrm{Dx}) \\
& \text {-2. } \forall \mathrm{x}(\mathrm{Px} \wedge \neg \mathrm{Ax}) \rightarrow \neg(\mathrm{Dx} \wedge \neg \mathrm{Cx}) \\
& \text {-3. } \mathrm{Pa} \wedge \neg \mathrm{Aa} \\
& \text { 4. } \neg \mathrm{Ca} \\
& \text { 5. } \mathrm{Pa} \quad \mathrm{E} \wedge, 3 \\
& \text { 6. } \mathrm{Pa} \rightarrow \mathrm{Da} \quad \mathrm{E} \forall, 1,5 \\
& \text { 7. } \mathrm{Da} \quad \mathrm{E} \rightarrow, 5,6 \\
& \text { 8. }(\mathrm{Pa} \wedge \neg \mathrm{Aa}) \rightarrow \neg(\mathrm{Da} \wedge \neg \mathrm{Ca}) \quad \mathrm{E} \forall, 2,3 \\
& \text { 9. } \neg(\mathrm{Da} \wedge \neg \mathrm{Ca}) \quad \mathrm{E} \rightarrow, 3,8 \\
& \text { 10. } \mathrm{Da} \wedge \neg \mathrm{Ca} \quad \mathrm{I} \wedge, 4,7 \\
& \text { 11. } \neg(\mathrm{Da} \wedge \neg \mathrm{Ca}) \wedge(\mathrm{Da} \wedge \neg \mathrm{Ca}) \quad \mathrm{I} \wedge, 9,10
\end{aligned}
$$

31 Utilizaré los siguientes predicados y símbolos: $\mathrm{P}=$ «es una persona»; $\mathrm{A}=$ «es una Administración Pública»; $\mathrm{D}=$ «tiene medios jurídicos a su disposición para hacer efectivos sus derechos»; $\mathrm{C}=$ «tiene acceso al proceso civil». Las reglas de inferencia empleadas quedaron indicadas en la transcripción del argumento en lenguaje natural. 

12. $\neg \neg \mathrm{Ca}$
$\mathrm{I} \neg, 4-11$
13. $\mathrm{Ca}$
$\mathrm{E} \neg, 12$

Tomando esas premisas como punto de partida, como creo que hace la Audiencia Provincial, el argumento por reducción al absurdo es lógicamente válido. Ahora bien, con esas mismas premisas parece más sencillo argumentar directamente:

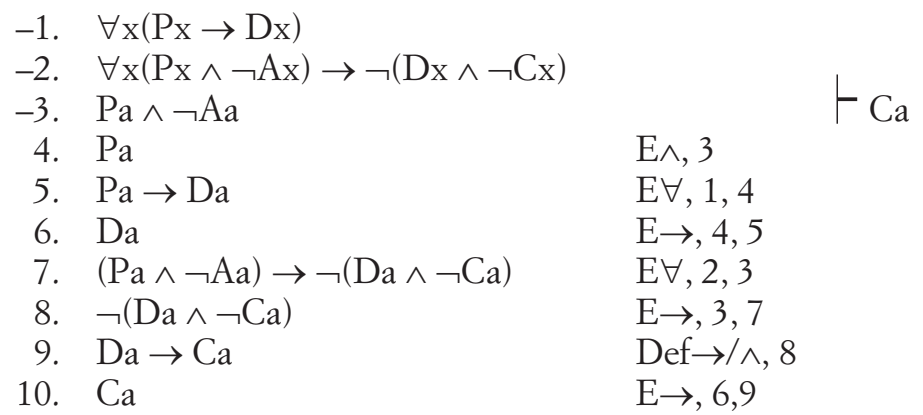

Expresado en lenguaje natural:

1. Todas las personas disponen de medios jurídicos (tienen medios jurídicos a su disposición) para hacer efectivo sus derechos (premisa).

2. Las personas que no son Administración Pública no disponen de medios jurídicos para hacer efectivos sus derechos cuando no tienen acceso al proceso civil (premisa).

3. Cierto sujeto $A$ es una persona y no es una Administración Pública (premisa).

4. A es una persona (se deduce de 3, con la regla de eliminación de la conjunción).

5. Si $A$ es una persona, entonces $A$ dispone de medios jurídicos para hacer efectivos sus derechos (se deduce de 1 y 4 , con la regla de eliminación del cuantificador universal).

6. A dispone de medios jurídicos para hacer efectivos sus derechos (se deduce de 4 y 5 , con la regla de eliminación del condicional).

7. Si $A$ es una persona y no es una Administración Pública, entonces $A$ no dispone de medios jurídicos para hacer efectivos sus derechos cuando no tiene acceso al proceso civil (se deduce de 2 y 3 , con la regla de eliminación del cuantificador universal).

8. A no dispone de medios jurídicos para hacer efectivos sus derechos cuando no tiene acceso al proceso civil (se deduce de 3 y 7 ).

9. $\mathrm{Si} A$ dispone de medios jurídicos para hacer efectivos sus derechos, entonces tiene acceso al proceso civil (se deduce de 8, por la interdefinición del condicional y la conjunción).

10. A tiene acceso al proceso civil (conclusión; se deduce de 6 y 9, con la regla de eliminación del condicional).

Es decir, el argumento asume unas premisas que conducen al fallo de la sentencia sin necesidad de invocar ningún absurdo. La Audiencia Provincial podría haber dicho:

Para concluir, puesto que la apelada ha de disponer de un medio para pedir el reintegro de lo abonado como sustituto y, al no ser Administración pública no dispone de otro que el acceso al proceso civil, no puede negársele dicho acceso. 
El empleo de una reducción al absurdo donde es posible un argumento directo puede ser un recurso retórico, que busca la complicidad del interlocutor respecto de la premisa de contraste en la que se apoya el argumento. Pero también puede esconder una petición de principio, cuando la premisa de contraste es parte de lo que se discute. En el ejemplo anterior, la idea de que todas las personas disponen de medios jurídicos para hacer efectivos sus derechos, que es la base del argumento expuesto, no es a su vez justificada o respaldada, y ni siquiera es mencionada, sino que sencillamente se usa como algo evidente que es innecesario enunciar y absurdo cuestionar. En este caso no hay petición de principio, porque esa idea no formaba parte de la discusión, y por otro lado es fácil de fundamentar (por ejemplo, recordando el derecho constitucional a la tutela judicial efectiva). Pero en muchos otros casos el recurso al absurdo es sospechoso.

\subsection{Reducción al absurdo y petición de principio}

En un buen argumento por reducción al absurdo, según vimos, la hipótesis rechazada (la negación de la tesis defendida) conduce hasta un resultado opuesto a una tesis previamente aceptada o premisa de contraste. El mejor modo de dar solidez al razonamiento, entonces, es explicitar la premisa de contraste y hacer visible su condición de tesis aceptada. En cambio, si la premisa de contraste no se enuncia desde el principio, sino que aparece en el curso del razonamiento, posiblemente el argumento no es una reducción al absurdo, sino una petición de principio. En la petitio principii se toma la conclusión como premisa, normalmente de modo implícito, por lo que el razonamiento es falaz. Para evitar la falacia, la reducción al absurdo ha de contar con premisas que tengan un fundamento independiente del propio argumento en el que intervienen. Dicho de otro modo, la aceptación de la premisa de contraste no puede seguirse de la reducción al absurdo, sino ésta de aquélla. Véase la siguiente muestra.

Auto de la Audiencia Provincial de Zaragoza (Sección 5. a) 409/2007, de 3 de julio

Se discute, entre otros asuntos, si al calcular la indemnización correspondiente a unas lesiones por accidente de circulación es posible sumar las consecuencias de una «incapacidad permanente total» y las de la «gran invalidez». La entidad aseguradora apelante argumentaba que ello supondría una duplicidad en el resarcimiento. La Audiencia explica en su Auto que si bien las resoluciones previas declararon que la víctima tenía una «incapacidad permanente total» (que inhabilita para la ocupación habitual), de la prueba practicada se desprende que era «absoluta» (para cualquier actividad), la cual «subsumiría o englobaría» aquélla; pero añade que no podría conceder ésta puesto que no fue pedida. Y continúa así (FD 4. ${ }^{\circ}$ ):

Ahora bien, siguiendo este criterio de la «subsunción», no cabe duda de que un «Gran inválido» abarca y engloba en su ámbito conceptual a aquél que no puede ejercer ninguna ocupación, ya que además de «eso», necesita a una tercera persona que le ayude.

Por tanto, conceder indemnización o corrección al alza por una secuela incapacitante y además hacerlo porque esa misma secuela implica la necesidad de ayuda de tercera persona, supone indemnizar dos veces el primer concepto, cuya gravedad ha sido absorbida por el segundo de mayor gravedad. 
De lo contrario, el Incapaz P. «Absoluto», como también —obviamente- lo es «total», tendría derecho a ambas indemnizaciones. Lo cual parece ser que nadie defiende en base al principio exegético de «reducción al absurdo».

Es decir, se argumenta que si las indemnizaciones por «incapacidad permanente total» y por «gran invalidez» fuesen acumulables (hipótesis), ello implicaría que también lo serían las indemnizaciones por «incapacidad permanente absoluta» y por «incapacidad permanente total», lo cual «parece ser que nadie defiende» porque es absurdo; y por eso hay que rechazar la hipótesis. Pero lo que también parece ser es que la Audiencia toma como premisa que no pueden sumarse las indemnizaciones por dos incapacidades cuando una engloba a la otra, y de ahí concluye, por supuesta reducción al absurdo, que no pueden sumarse las indemnizaciones por dos incapacidades cuando una engloba a la otra. Sin perjuicio de que sea efectivamente absurdo que puedan acumularse ambas indemnizaciones, lo que se discutía en este caso era precisamente eso, por lo que la reducción al absurdo no es aquí un buen argumento.

\subsection{Desacuerdos sobre lo absurdo}

El argumento por reducción al absurdo funciona sobre la base de que tanto el proponente como sus interlocutores consideran inadmisible la conclusión a la que conduce la hipótesis rechazada, hasta el punto de que este común rechazo es una premisa del argumento (que no suele hacerse explícita). Como ya he apuntado, es normal en la reducción al absurdo presente en la motivación de las decisiones jurídicas que lo que se declara o presume absurdo lo sea efectivamente a juicio de cualquiera que examine el caso sin prejuicios. Sin embargo, hay muchas ocasiones en las cuales lo que al Tribunal le parece una tesis claramente inadmisible no lo es tanto, como hemos podido ver en anteriores ejemplos. En algunos casos, además, los desacuerdos sobre lo que se considera absurdo se ponen de manifiesto en las propias sentencias, al reflejar los argumentos de las partes. Veamos otra muestra.

Sentencia del Tribunal Constitucional 259/2007, de 19 de diciembre de 2007

Se resuelve un recurso de inconstitucionalidad interpuesto contra diversos preceptos de la Ley Orgánica 8/2000, de 22 de diciembre, de reforma de la Ley Orgánica 4/2000, de 11 de enero, sobre derechos y libertades de los extranjeros en España y su integración social. Aquí nos interesa el debate sobre la nueva redacción del art. 11 de la LO 4/2000:

1. Los extranjeros tendrán derecho a sindicarse libremente o a afiliarse a una organización profesional, en las mismas condiciones que los trabajadores españoles, que podrán ejercer cuando obtengan autorización de estancia o residencia en España.

2. De igual modo, cuando estén autorizados a trabajar, podrán ejercer el derecho de huelga.

El recurrente sostenía que esta redacción era contraria a la Constitución y a diversos pactos internacionales, al hacer depender el derecho de sindicación de los extranjeros de la autorización de estancia o residencia en España y el derecho de huelga 
de la autorización para trabajar. En cambio, el abogado del Estado — según resume la sentencia- objetó lo siguiente:

$[L]$ os extranjeros no autorizados para estar o residir en España no están autorizados tampoco para trabajar válidamente. Y ello porque constituiría un absurdo irreconciliable con el sentido común permitir que quien no está autorizado a trabajar pudiera ejercer el medio de presión sobre el empresario que le otorga el derecho fundamental a la huelga.

Con independencia de la defectuosa secuencia lógica del párrafo, queda claro que a juicio del abogado del Estado es evidente que sólo puede tener derecho de huelga quien está autorizado a trabajar, que lo contrario sería absurdo y que cualquier interpretación de la Constitución que lo implique está equivocada. En contraste, para el Tribunal Constitucional excluir del derecho de huelga a los extranjeros que trabajen sin autorización administrativa es contrario al art. 28.2 CE, por lo que declara inconstitucional el inciso «cuando estén autorizados a trabajar» del art. 11.2 citado. Al respecto, el Tribunal argumenta así (FJ 7. $\left.{ }^{\circ}\right)$ :

La concepción criticada no se corresponde con la titularidad del derecho fundamental ejercitable en la defensa de los intereses de los trabajadores, entre los que puede encontrarse la consecución de la plena regularidad de su situación administrativa. De ahí que no resulte absurdo, como alega el abogado del Estado, reconocer este concreto derecho a los extranjeros no autorizados administrativamente para trabajar en España, quienes pueden ejercerlo para la defensa de sus intereses, entre los que puede encontrarse la regularidad de su situación, pese a la irregularidad de la misma. De esta forma la norma aquí controvertida no garantiza la debida protección de los intereses que, a través del reconocimiento constitucional del derecho de huelga, se tratan de satisfacer.

Este ejemplo ilustra sobre la posibilidad de discrepancias en lo que se considera inaceptable y sobre algunos otros aspectos problemáticos ya señalados en la reducción al absurdo. Es un modo de argumentar que se presenta con la apariencia de razonamiento lógico - no en vano su origen es una demostración deductiva lógica y matemática- pero a menudo es sólo un recurso retórico o dialéctico cuya eficacia se basa en emociones. El argumento deja de tener fuerza cuando falla su lógica interna y también cuando sus premisas no son aceptadas, en particular cuando lo que toma como absurdo es discutible (como en el ejemplo anterior y en muchas otras interpretaciones de lo que evidentemente exige el ordenamiento jurídico) o discutido en el propio caso (petición de principio). Y aun siendo válido en su lógica interna y suficientemente sólido en sus premisas, el argumento por reducción al absurdo puede ser un rodeo innecesario. Pero otras veces, como hemos visto, resulta ser una herramienta poderosa y eficaz para la argumentación jurídica.

\section{REFERENCIAS}

AgUiRRE, 2002: «La abducción en Aristóteles: Su papel en la lógica y en su teoría de la ciencia», Revista de Filosofía y Teoría Política, Anexo 2004, IV Jornadas de Investigación en Filosofía 7-9/11/2002, La Plata.

AleXY [1978] 1989: Theorie der juristischen Argumentation, Frankfurt, Suhrkamp, 1978. Se cita por la trad. esp. de M. Atienza e I. Espejo, Teoría de la argumentación jurídica. La teoría del discurso racional como teoría de la fundamentación jurídica, Madrid: Centro de Estudios Constitucionales. 
APPIAH, 2003: Thinking It Through. An Introduction to Contemporary Philosophy, Oxford: Oxford University Press.

ARIstóteles (ed.), 1988: «Analíticos Primeros», en Tratados de lógica (Órganon), vol. II, introd. y trad. de M. Candel, Madrid: Gredos, 82-297.

Asís RoIG, 1998: Sobre el razonamiento judicial, Madrid: MacGraw-Hill.

ATIENZA, 2006: El derecho como argumentación, Barcelona: Ariel.

Beuchot, 1998: «Abducción y analogía», en C. S. Peirce y la abducción (monográfico), Analogía Filosófica, XX (1), 57-68. Ahora en bttp://www.unav.es/gep/AN/ANIndice.html.

Diederichsen, 1973: «Die "Reductio Ad Absurdum" in Der Jurisprudenz», en P. Paulus, U. DiederichSEN y C.-W. CANARIS (eds.), Festschrift Für Karl Larenz Zum 70. Geburtstag, München, C. H. Beck'sche Verlagsbuchhandlung, 155-179.

EZQUIAGA, 1994: «Argumentos interpretativos y el postulado del legislador racional», Isonomía, 1, 69-98.

EZQUiAGa GANUZAs, 1987: La argumentación en la justicia constitucional española, Oñati: Instituto Vasco de Administración Pública.

FERNÁNDEZ AbAD y EsTREMERA CEBRIÁN, 1995: «Argumentación apagógica, a fortiori y económica», en CALVO GARCía (ed.), Interpretación y argumentación jurídica. Trabajos del Seminario de Metodología Jurídica (vol. I), Zaragoza: Prensas Universitarias de Zaragoza, 95-106.

FETERIS, 2009: «Teleological Argumentation», IVR Encyclopaedia of Jurisprudence, Legal Theory and Philosopby of Law, accessible en bttp://ivr-enc.info.

GARCíA AMADO, 2010: «Sobre la derrotabilidad de las normas jurídicas», en BONORINO (ed.), Teoría del derecho y decisión judicial [s.1.], Bubok, 179-204.

GASCÓN y GARCÍA FigueroA, 2005: La argumentación en el derecho, Lima: Palestra (2. ${ }^{\text {e ed.). }}$

GuASTINI [1996] 1999: Distinguendo. Studi di teoria e metateoria del diritto, Torino: Giappicheli, 1996. Se cita por la trad. esp. de J. Ferrer i Beltrán, Distinguiendo. Estudios de teoría y metateoría del derecho, Barcelona: Gedisa.

JANSEN, 2007: «Refuting a Standpoint by Appealing to Its Outcomes: Reductio ad Absurdum vs. Argument from Consequences», Informal Logic, 27 (3) 249-266.

Kloosterhuis, 2007: «Ad Absurdum Arguments in Legal Decisions», en Aguiló Regla (ed.), Logic, Argumentation and Interpretation/Lógica, Argumentación e Interpretación, Archiv für Rechts-und Sozialphilosophie, Beiheft 110, 68-74.

KLUG [1982], 1990: Juristische Logic, Berlin/Heildelbert: Springer, 1982 (4. ${ }^{\text {a }}$ ed.). Se cita por la trad. esp. de J. C. Gardella, Lógica jurídica, Bogotá: Temis.

MACCormick, 1994: Legal Reasoning and Legal Theory [1978], Oxford: Clarendon Press.

Martínez Zorrilla, 2010: Metodología jurídica y argumentación, Madrid: Marcial Pons.

NiNO, 1989: Consideraciones sobre la dogmática jurídica, México: UNAM.

RESCHER, 2005: «Reductio ad Absurdum», Internet Encyclopedia of Philosophy, www.iep.utm. $e d u$.

SARTOR, 2005: «Legal Reasoning. A Cognitive Approach to the Law», en PATTARO (coord.), $A$ Treatise of Legal Philosophy and General Jurisprudence, vol. 5, Dordrecht: Springer.

STELMACH y BROŻEK, 2006: Methods of Legal Reasoning, Dordrecht: Springer.

TARELLO, 1980: L'interpretazione della legge, Milano: Giuffrè.

WACKE, 2007: «La consideración de las consecuencias de las decisiones jurídicas mediante "deductio ad absurdum" (en derecho romano y en derecho moderno)», Seminarios complutenses de derecho romano. Revista complutense de derecho romano y tradición romanística, 20-21 (2007-2008), 451-480. 
Weston [1992] 2006: A Rulebook for Arguments, Indianapolis: Hackett, 1992 (2.a ed.). Hay

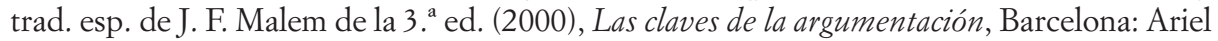
(10. ${ }^{a}$ ed., 12. ${ }^{a}$ reimpr.).

ZuLETA, 2005: «La fundamentación de las sentencias judiciales. Una crítica a la teoría deductivista», Isonomía, 23, 59-95.

Nota final: Muchas de las sentencias citadas en el texto pueden consultarse online en el Repertorio Oficial de Jurisprudencia (ROJ) del Centro de Documentación Judicial (CENDOJ), que gestiona el Consejo General del Poder Judicial: bttp://www. poderjudicial.es/search/indexAN.jsp. 